\title{
Functional Metabolic Mapping During Forelimb Movement in Rat. I. Stimulation of Motor Cortex
}

\author{
Robert C. Collins, Emily M. Santori, Terry Der, Arthur W. Toga, and Eric W. Lothman \\ Department of Neurology and Neurological Surgery and the McDonnell Center for the Study of Higher \\ Brain Functions, Washington University, St. Louis, Missouri 63110
}

The quantitative ${ }^{14} \mathrm{C}$-deoxyglucose (DG) autoradiographic technique has been used to study changes in cerebral metabolism during forelimb movements induced by graded stimulation of motor cortex. Experiments were directed at studying basic physiologic and anatomic aspects of the metabolic changes. Single shocks caused movement without metabolic change, whereas lowfrequency trains caused seizures. Repetitive high-frequency train stimuli of short duration ( $500 \mathrm{~Hz}$ for $20 \mathrm{msec}$ ) caused jerk movements coupled with DG uptake in pathways. With stimulation of the forelimb motor zone at frequencies of $15-30 / \mathrm{min}$ there was prominent activation of cortical columns and strips in ipsilateral SI, SII, and MII, and contralateral MI and SI. Higher frequencies $(120 / \mathrm{min})$ were required to cause significant changes in DG in subcortical circuits. The most prominent changes occurred within a longitudinal corridor in dorsal thalamus and a ventral corridor in second-order sites in basal ganglia. Metabolic activation also occurred in contralateral cerebellum, the cuneate nucleus, and dorsal horn of the cervical spinal cord. Changes in these latter two sites were largely eliminated by removing feedback sensory activity. Stimulation of the forelimb sensory zone activated different sites in caudatoputamen and thalamus but similar zones in midbrain and cerebellum. The magnitude of the metabolic response in distant sites depended on the frequency of cortical stimulation. Different frequencyresponse relationships in different sites seemed to reflect the nature of the cortical input as well as differential effects of anesthesia. The pattern of the metabolic response was studied by comparing sites of activation with sites of the anatomic projections from motor and sensory cortical zones. ${ }^{3} \mathrm{H}$ - and ${ }^{14} \mathrm{C}$-labeled amino acids were used to map the site and relative strength of pathways. Results revealed good correlation between the site of anatomic projection and the site of DG uptake but no consistent relationship between the relative strength of a projection and the magnitude of metabolic change within its field.

Changes in glucose utilization with metabolic mapping experiments depend on the nature, strength, and frequency of stimulation; the site and nature of anatomic projection; the effects of anesthesia; and the strength of sensory feedback associated with the induced behavior.

Knowledge of the functional organization of motor systems in rat has been recently expanded by physiologic and anatomic

\footnotetext{
Keceived May 13, 1985; revised Aug. 5, 1985; accepted Aug. 12, 1985.

We wish to thank Mrs. Lymer for technical assistance and Mrs. Pigg and Mrs. Chandler for their help in the preparation of the manuscript. This work was supported by United States Public Health Service Grant NS 14834 and a Klingenstein Senior Fellowship (to R.C.C.).

Correspondence should be addressed to Robert C. Collins, Department of Neurology, Box 8111, Washington University Medical School, St. Louis, MO 63110.

'Present address: Department of Neurology, University of Virginia Medical Center, Charlottesville, VA 22908.
}

Copyright (C) 1986 Society for Neuroscience 0270-6474/86/020448-15\$02.00/0 studies of neocortex. Original studies by Woolsey and colleagues (Settlage et al., 1949; Woolsey, 1958) were later refined by Hall and Lindholm (1974) and more recently by Donoghue and Wise (1982) and Sanderson et al. (1984). Using intracortical stimulation, Donoghue and Wise localized the neocortex responsible for forelimb movement to a $2 \times 4 \mathrm{~mm}$ strip located rostral and lateral to bregma. Anterior and medially, the area was comprised of agranular cortex, but its posterior and lateral segment extended within granular cortex typical of the somatosensory receptive fields of SI (SmI of Donoghue et al., 1979; Sanderson et al., 1984; Welker, 1971; Welker et al., 1982). Neafsey and Sievert (1982) have reported finding a second smaller forelimb arca for digit movement near the anterior pole of motor cortex of rat. The relationship between this second motor area, MII, and $\mathrm{MI}$ in rat is uncertain.

Corticocortical as well as subcortical connections of rat motor cortex have been studied with both anterograde and retrograde tracing techniques (Akers and Killackey, 1978; Donoghue and Parham, 1983; Isseroff et al., 1984; Krettek and Price, 1977; Wise and Jones, 1976, 1977; Wise et al. 1979). These studies have resulted in a fairly detailed understanding at the lightmicroscopic level of first-order input-output connections of rat motor cortex. Additional experiments have been directed at learning which of these circuits are activated and utilized during forelimb movements induced by topical convulsants (Collins, 1978a, b; Collins et al., 1976) or intracortical stimulation (Collins et al., 1980; Sharp, 1984; Sharp and Evans, 1982; Sharp and Ryan, 1984). These latter studies measured local changes in ${ }^{14} \mathrm{C}$-deoxyglucose (DG) metabolism in cortical and subcortical circuits. These revealed functional metabolic changes in sensory and reticular thalamic, midbrain, and pontine nuclei, as well as in circuits in basal ganglia and cerebellum. These metabolic findings suggest broad definitions of the motor system as those neuroanatomical sites that become functionally active during a movement.

The present studies were undertaken to further define the functional anatomy of forelimb movement in rat using the quantitative DG autoradiographic technique (Sokoloff et al., 1977) in combination with localized electrical stimulation of forelimb neocortex. In the first study we were interested in three questions: (1) What is the anatomic pattern of the functional metabolic changes in response to intracortical stimulation of forelimb motor cortex? (2) How does the pattern and intensity of the metabolic response vary with changes in stimulus parameters? (3) How does the distributed pattern of the response relate to corticofugal pathways from the stimulus site? In our second study (Santori et al., 1986), we examined how sensory activity ascending from a moving forelimb causes changes in metabolism in central forelimb pathways. Part of this work has appeared in abstract form (Collins and Der, 1979; Collins et al., 1980; Der et al., 1983). 


\section{Materials and Methods \\ Intracortical stimulation}

Male Sprague-Dawley rats weighing 280-320 gm were anesthetized with halothane, and PE-50 catheters were inserted into the femoral artery and vein. The rat was then placed in a stereotaxic frame, and a dental drill was used to expose a wide arca of frontal and parictal cortcx for stimulus-response mapping, or a small 2-mm-diameter burr hole was made for restricted stimulation of selected sites. The electrode track was located after each experiment using histological stains of serial sections. For purposes of mapping, the electrode position was determined relative to the bony bregma, anterior commissure, and the medial edge of the granule cell layer IV. For intracortical stimulation we used concentric bipolar electrodes: lower tip $100 \times 250 \mu \mathrm{m}$ exposure, upper shoulder $200 \times 250 \mu \mathrm{m}$ exposure, tip separation $750 \mu \mathrm{m}$ (Rhodes Electronics, Duarte, CA).

For our mapping experiments a small incision was made in the dura, and the electrode was advanced in $100 \mu \mathrm{m}$ increments for stimulation or recording. Individual stimuli were $0.2 \mathrm{msec}$ duration square wave pulses. The other stimulation parameters were varied in individual experiments to assess the effect on metabolic response and forclimb movement. Variations in stimulus configuration (single shocks versus trains), stimulus strength, and stimuli number were studied and are given in the results.

\section{Evoked potentials}

Single 0.01 -in.-diameter wire electrodes were used to deliver surface or subcutaneous stimuli to the forepaw contralateral to the cortical electrode: bipolar pulses, $0.1 \mathrm{msec}$ duration, $10 \mathrm{~V}, 3 / \mathrm{sec}$. The cortical potentials from 128 stimuli were averaged on a model 527 Nicolet averager using a $225 \mathrm{msec}$ sweep speed. The amplitude of the cortical potential measured with the bipolar electrode across layer IV was recorded for multiple cortical points during stimulus response mapping.

\section{$D G$ autoradiography}

Forty animals were studied under light halothane anesthesia, characterized by the presence of forelimb withdrawal to light pinch. An additional 12 animals were studied $3 \mathrm{hr}$ after halothane while lightly restrained on a lead brick. $1-{ }^{14} \mathrm{C}$-2-deoxyglucose $(50 \mathrm{mCi} / \mathrm{mmol}$; American Radiolabeled Chemical and Pathfinder Laboratory, St. Louis) was given intravenously $(6 \mu \mathrm{Ci} / 100 \mathrm{gm}$ rat $) 2 \mathrm{~min}$ after the stimulus-induced forelimb movement had been started. Stimulation was continued for the duration of the study. Timed arterial samples were collected for the determination of plasma precursor curve until time of sacrifice at 50 min. Brains were perfused and fixed with $3.3 \%$ paraformaldehyde in $0.1 \mathrm{M}$ phosphate, $\mathrm{pH} 7.3$, and then frozen. These were serially sectioned coronally or horizontally at $20 \mu \mathrm{m}$ thickness saving triplicate sections every $200 \mu \mathrm{m}$. Sections were processed for quantitative autoradiography on Kodak clear XAR film following the methods of Sokoloff et al. (1977). Densitometric measurements were made with a Leitz microscope-photometer or a computer-based image analyzer in the Laboratory of Neuro Imaging at Washington University (Toga et al., 1984). Individual sections were subsequently stained with thionin to aid in the analysis of anatomical features.

\section{Corticofugal projections}

Projections from forelimb motor and sensory cortex were mapped using the radioactive amino acid tracing technique. Both ${ }^{3} \mathrm{H}$ and ${ }^{14} \mathrm{C}$ isotopes were used. For studying fine details of terminal fields, small volumes of ${ }^{3} \mathrm{H}$-proline (30-60 $\mathrm{nl} ; 4-8 \mu \mathrm{Ci}$ ) were injected over $15 \mathrm{~min}$ into the motor or sensory cortical fields and animals $(n=6)$ were allowed to survive $1-9 \mathrm{~d}$ before processing for emulsion autoradiography. Small injections of ${ }^{14} \mathrm{C}$-proline, -leucine, or -alanine (30-100 $\mathrm{nl}, 0.03-0.10$ $\mu \mathrm{Ci})$ were used to determine the relative strength of cortical projections into the different terminal fields. These animals $(n=15)$ were perfused and fixed with $3.3 \%$ paraformaldehyde at the time of sacrifice, and brains were serially sectioned and submitted for quantitative film autoradiography along with radioactive ${ }^{14} \mathrm{C}$-methylmethacrylate standards. The concentration of radioactivity $(n \mathrm{Ci} / \mathrm{gm})$ was measured for each terminal field, and the volume of the projection was determined by planimetric techniques. The amount of radioactivity transported into the whole terminal field was then computed (radioactivity $=$ concentration $\times$ volume). These techniques were used to compare the relative strength of different projections from a single site of isotope injection. As discussed in more detail previously (Toga and Collins, 1981), this approach can only be used "semiquantitatively," since it is unknown whether all projection neurons in any one site receive, take up, synthesize, and transport the same amount of isotope at the same rate. In addition, distances between terminal fields would also influence the amount received at any one point in time. These difficulties are partly circumvented in the present study by drawing conclusions from the data of many animals studied with different amino acids, volumes of injection, and sacrifice times.

\section{Results}

\section{Changes in functional DG metabolism}

\section{Forelimb cortical map}

In preliminary experiments we determined the stereotaxic coordinates of sensory and motor cortex by electrophysiological criteria. Issing a bipolar electrode we mapped the frontal and parietal cortex for low-threshold movements in response to intracortical stimulation. During each penetration we also searched for high-amplitude sensory evoked potentials in response to forelimb stimulation. The bipolar electrode used did not allow as fine-grained a localization as can be achieved with fine-tipped microelectrodes, but they served our purpose for localization of appropriate fields for stimulation and metabolic mapping. With stimulation in motor cortex the thresholds for local and transcallosal evoked potentials were similar in anesthetized and awake animals $(20 \pm 10 \mu \mathrm{A})$, but the threshold for twitch response was 2.4 times higher in anesthetized animals $(450 \pm 150$ vs $188 \pm$ $67 \mu \mathrm{A}$ ). In both cases the response consisted of dorsal flexion at wrist and elbow with occasional spreading of digits. In agreement with previous workers (Donoghue and Wise, 1982; Hall and Lindholm 1974; Sanderson et al., 1984), we found that lowthreshold motor responses extended posteriorly and laterally into a portion of granular cortex.

The potentials evoked in the cortex in response to forclimb movements elicited by peripheral stimulation were complex, polyphasic events. The most prominent wave was a positivegoing transient at 25-30 msec that had its maximal amplitude over anterior fields of granular cortex in all animals. In addition, the wave form reversed polarity across layer IV, indicating activity here as the source of the potential. For each animal studied, the amplitude of the evoked potential for each penetration (8-15 total) was mapped as the percentage of the maximal evoked potential found in that animal. Similarly, the stimulus intensity ncccssary to induce forelimb movement in each penetration was expressed as the percentage of the threshold current found at the most sensitive motor site. A representative cortical map is illustrated in Figure 1. Based on these maps, we studied motor cortex in subsequent animals by stimulating at a point $2.2 \mathrm{~mm}$ anterior and $2.5 \mathrm{~mm}$ lateral to bregma; and sensory cortex 0.5 $\mathrm{mm}$ anterior and $4.0 \mathrm{~mm}$ lateral. In addition, the spread of the stimulation focus was determined in each experiment by plotting the metabolic focus (DG autoradiogram) within its histological zones (thionin-stained sections-see below).

\section{Stimulation parameters vs metabolic response}

Different parameters of stimulation were tested to determine the relationship between the type, strength, and frequency of stimulation and the functional metabolic response in cortical and subcortical circuits. Twenty animals were studied under light halothane anesthesia using 12 different paradigms (Table 1). Stimulation with individual pulses up to $150 / \mathrm{min}$ caused only local metabolic activation of cortex without movement. Stimulation with repetitive trains of shocks at 5 or $50 \mathrm{~Hz}$ caused metabolic activation within cortex, but raising current strength or train frequency to levels sufficient to cause forelimb movement frequently resulted in seizures. Stimulation with highfrequency trains $(500 \mathrm{~Hz})$ of short pulses $(0.2 \mathrm{msec})$ for short train duration $(20 \mathrm{msec})$ was most effective in causing discrete 


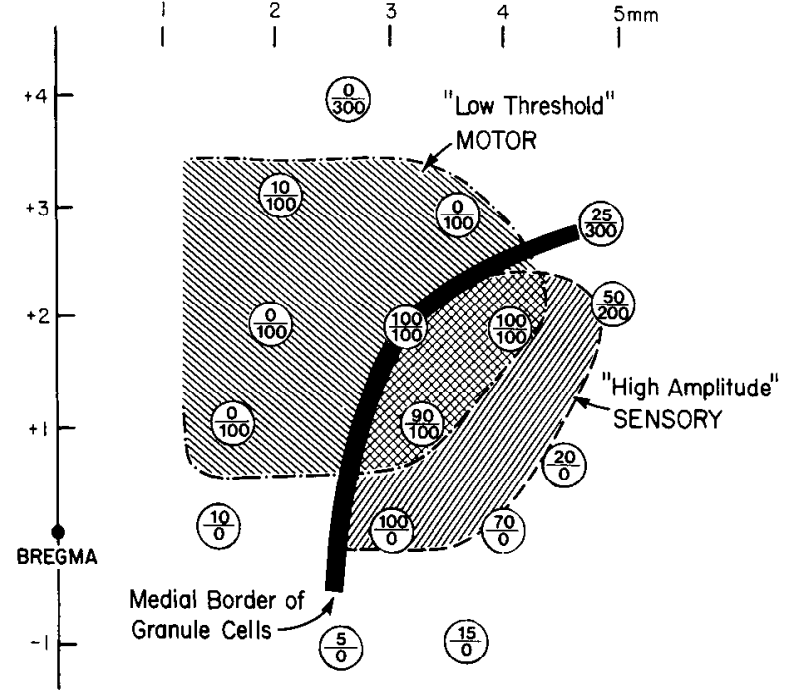

Figure 1. Forelimb cortex stimulus-response and evoked potential map. A view of the dorsal surface of cortex is shown with the bregma serving as the zero point of orientation. The data represent separate animal studies. The numerator of each fraction represents the maximum percentage of the evoked potential measured in the center of the sensory zone; the denominator represents the percentage of the threshold stimulus used to induce a forelimb jerk in the center of the motor zone. 0 indicates failure of motor response. Electrode tracks and the medial border of the granular zone were localized using thionin stains.

forelimb jerks and activation of cortical and subcortical circuits. By adjusting the stimulus strength in each animal to levels slightly above the threshold necessary to cause jerk movement, it became possible to study the effect of increasing the stimulus frequency on the site and intensity of functional metabolic responses. In anesthetized animals it was possible to increase the rate to 180 trains/min, but unanesthetized animals proved sen- sitive to repetitive train stimuli and commonly developed seizures with rates much above $150 / \mathrm{min}$. Animals that had seizures were excluded from analysis.

\section{Corticocortical circuits}

Using a standard stimulus paradigm $(500 \mathrm{~Hz}, 0.2 \mathrm{msec}$ pulses, $20 \mathrm{msec}$ train duration) to produce mild wrist extensor jerks, we found intracortical stimulation caused prominent metabolic activation at the stimulation site in forelimb motor cortex and in distant cortical fields. With increasing frequency of stimulation, the metabolic focus enlarged and distant columnar and strip profiles became more numerous and prominent (Fig. 2). There were no consistent differences between anesthetized and awake animals in the pattern of activation, and only a mild depression in the intensity of the response in the anesthetized group (Table 2). When analyzed topographically, the pattern showed activation beyond the focus to ipsilateral MI, SI, and SII, and contralateral MI and SI. In several animals there was also a separate patch of activation anteriorly, probably lying in the zone proposed by Neafsey and Sievert (1982) as MII (Fig. $5 A$ ). Although most animals showed increased metabolism in these sites, the fine spatial details of topography were highly variable among animals, such that a rigid or dominant pattern was not evident (Fig. 2).

Histological analysis of individual metabolic profiles in SI on coronal sections suggested corticocortical activation occurred within the dysgranular zones that lie between the dense clusters of layer IV granule cells (Fig. 3, $A, B$ ). This finding was supported by analyzing flattened horizontal sections of cortex, where the demarkations of layer IV granule cells could be recognized more clearly (Fig. 3, $C, D$ ).

\section{Subcortical circuits: basal ganglia and thalamus}

Stimulation of forelimb motor cortex resulted in prominent activation of ipsilateral dorsolateral caudatoputamen, globus pallidus externa and interna (endopeduncular nucleus), and the substantia nigra, pars reticulata (Figs. 4 and 5). Two sites of

\section{Table 1. Effects of varying stimulation parameters of motor cortex on forelimb movement and changes in DG utilization (light halothane} anesthesia)

Stimulation variables

A. Vary stimulus strength

Constant stimulus number (150/min)

With constant configuration

( $50 \mathrm{~Hz}$ train, $1 \mathrm{sec}$ duration, every $20 \mathrm{sec}$ )

Threshold $(T)=$ ipsilateral cortical evoked potential

B. Vary stimulus configuration Constant stimulus number $(150 / \mathrm{min})$ With constant stimulus strength

C. Vary stimuli number

Constant configuration $(500 \mathrm{~Hz}$ train, 20 msec duration)

With stimulus strength set to produce just noticeable forelimb jerk (400-500 $\mu \mathrm{A})$

Metabolic response

\begin{tabular}{lll}
\hline Stimula- & Cortico- & Sub- \\
tion & cortical & cortical \\
focus & circuits & circuits \\
\hline
\end{tabular}

movements

1. $4 \times T(100 \mu \mathrm{A})$

2. $30 \times T(450 \mu \mathrm{A})$

3. $100 \times T(2000 \mu \mathrm{A})$
0

0

$50 \%$ seizures
$++$

$+$

$++$
0

0 $++$
1. $2.5 \mathrm{~Hz}$ single pulses

2. $5 \mathrm{~Hz}, 1 \mathrm{sec}$, every $2 \mathrm{sec}$

3. $50 \mathrm{~Hz}, 1 \mathrm{sec}$, every $20 \mathrm{sec}$

4. $500 \mathrm{~Hz}, 20 \mathrm{msec}$, every $4 \mathrm{sec}$

1. once/4 sec

2. once $/ 2 \mathrm{sec}$

3. once/sec

4. $2 / \mathrm{sec}$

5. $3 / \mathrm{sec}$

$\begin{array}{lll} & 0 & 0 \\ +++ & 0 & 0 \\ ++ & ++ & + \\ ++ & ++ & 0 \\ & & \\ + & + & 0 \\ + & + & 0 \\ ++ & ++ & + \\ +++ & +++ & ++ \\ +++ & +++ & +++\end{array}$


ANESTHETIZED $15 / \mathrm{min}$

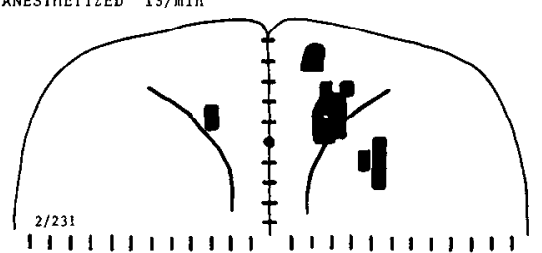

ANESTHETIZED $60 / \mathrm{min}$

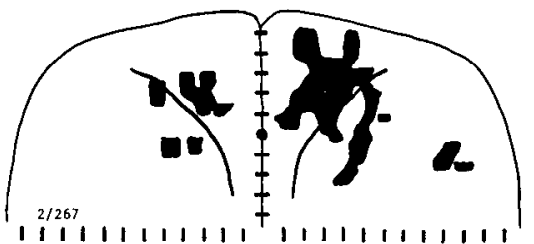

ANESTHETIZED $\quad 120 / m$ in

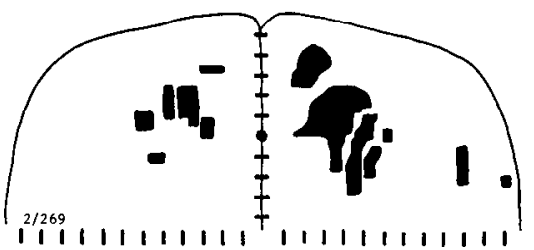

ANESTHETIZED $180 / \mathrm{min}$

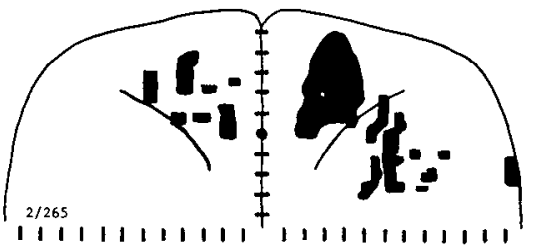

AWAKE $15 /$ min

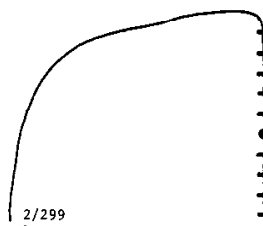

$\mathbf{I} \mathbf{1} \mathbf{~}$

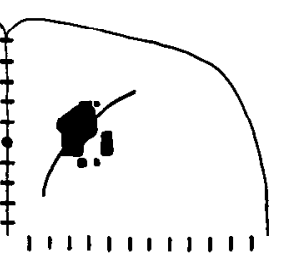

AWAKE $60 / \mathrm{min}$

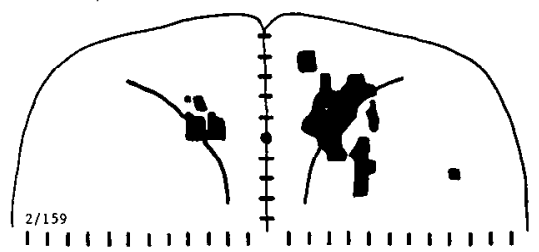

AWAKE $120 / m$ in

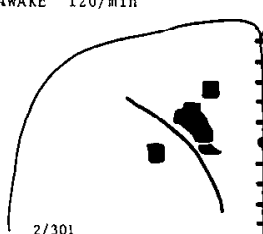

$1^{2} \hat{1}^{301}|1| 1|1| 11^{t}|1| 1|1| 1|1| 1$

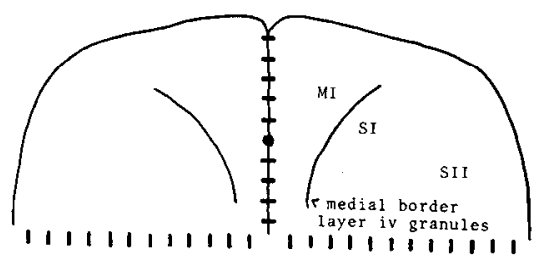

Figure 2. Cortical metabolic maps. Coronal sections from DG autoradiograms and thionin-stained sections were enlarged using a projector and then drawn on a millimeter map using the bregma and the electrode track as orienting points. Individual metabolic maps are shown from experiments using different frequencies of stimulation of forelimb motor cortex. activation were apparent in the substantia nigra, pars reticulata. One was among the neurons situated in the anterior pole of the nucleus lying within the internal capsule. The other site was within the body of the nucleus above the peduncle. Figure $4 F$ depicts the corridor of activity found running from globus pallidus interna, anteriorly to substantia nigra, pars reticulata posteriorly. With increasing frequency of stimulation, metabolism also increased in homotopic sites in contralateral basal gangliain particular in dorsolateral caudate, globus pallidus, and substantia nigra (Fig. 5, $B, C, I$ ).

Metabolism increased in thalamus within the anterior third of nucleus reticularis and in a longitudinal corridor within the body of the thalamus (Figs. $4, A-C ; 5$ ). This ran anteriorly from ventralis anterior, through ventralis lateralis proper, and ended in a long tail overlapping the medial part of the posterior thalamic nucleus and the lateral aspects of the parafasicular nucleus. This longitudinal pattern of activation was contiguous throughout, but with hot spots occurring in ventralis lateralis and the nucleus posterior. At high stimulation frequencies, weak activation was seen in the ventral medial nucleus and adjacent fields in zona incerta (Fig. $5 G$, middle arrow, and $7 B$ ).

In a few animals, metabolism was increased within the forelimb sector of the ventral basal complex (see Fig. $5 F$, middle arrow). Analysis of the stimulus site in these animals revealed that the metabolic focus included the granular, or sensory overlap, zone of forelimb cortex, implying direct corticofugal activation. The role of sensory feedback from the moving limb in altering thalamic metabolism is evaluated in the subsequent paper (Santori et al., 1986).

\section{Subcortical circuits: midbrain to spinal cord}

Evidence for metabolic activation beyond thalamus was inconsistent in anesthetized animals stimulated below $120 \mathrm{trains} / \mathrm{min}$.
In awake animals there was a modest $15-25 \%$ increase in metabolism in the anterior portion of the red nucleus and bilaterally in subthalamic nuclei (summarized in Fig. $4 F$ ). Light activation was also seen ipsilaterally in the deep mesencephalic nucleus (Fig. $5 I$ ), in the lateral posterior zones of the deep layers of superior colliculus, and in basal pontine nuclei. In the contralateral hemisphere of the cerebellum, there was metabolic activation in the anterior lobe extending from the lateral aspects of lobule 5 into the medial aspect of simplex. Posteriorly, a more intense pattern of activation occurred in the copula pyramis and paramedian lobule (Fig. $6 \mathrm{~A}$ ). The metabolic change was confined to the granule cell layer and was homogenous throughout. There was no consistent activation of deep cerebellar nuclei in these animals.

Stimulation of forelimb motor cortex also caused activation of metabolism in the contralateral cuneate nucleus and the dorsal gray of the cervical spinal cord (Fig. 6, B, C). The latter change occurred primarily in the medial aspects of lamina III$\mathrm{V}$. There was no consistent change in metabolism in the anterior horn of gray matter.

Since metabolic changes in the spinal cord, cuneate, and cerebellum could be due to sensory activity ascending from the moving forelimb (see Santori et al., 1986) rather than from activity descending from the cortex, we studied a series of rats after sectioning the brachial plexus. First, electrodes were cemented into place in the motor cortex and transcallosal homotopic cortex. On the next day, the stimulation threshold for forelimb movement was determined and the transcallosal evoked potential was monitored. Under anesthesia the brachial plexus was then transected in the axilla and catheters were inserted into femoral vessels for DG studies. After recovery from anesthesia, rats were stimulated above threshold at 120-150 trains/ min. There was no movement, but the transcortical evoked 

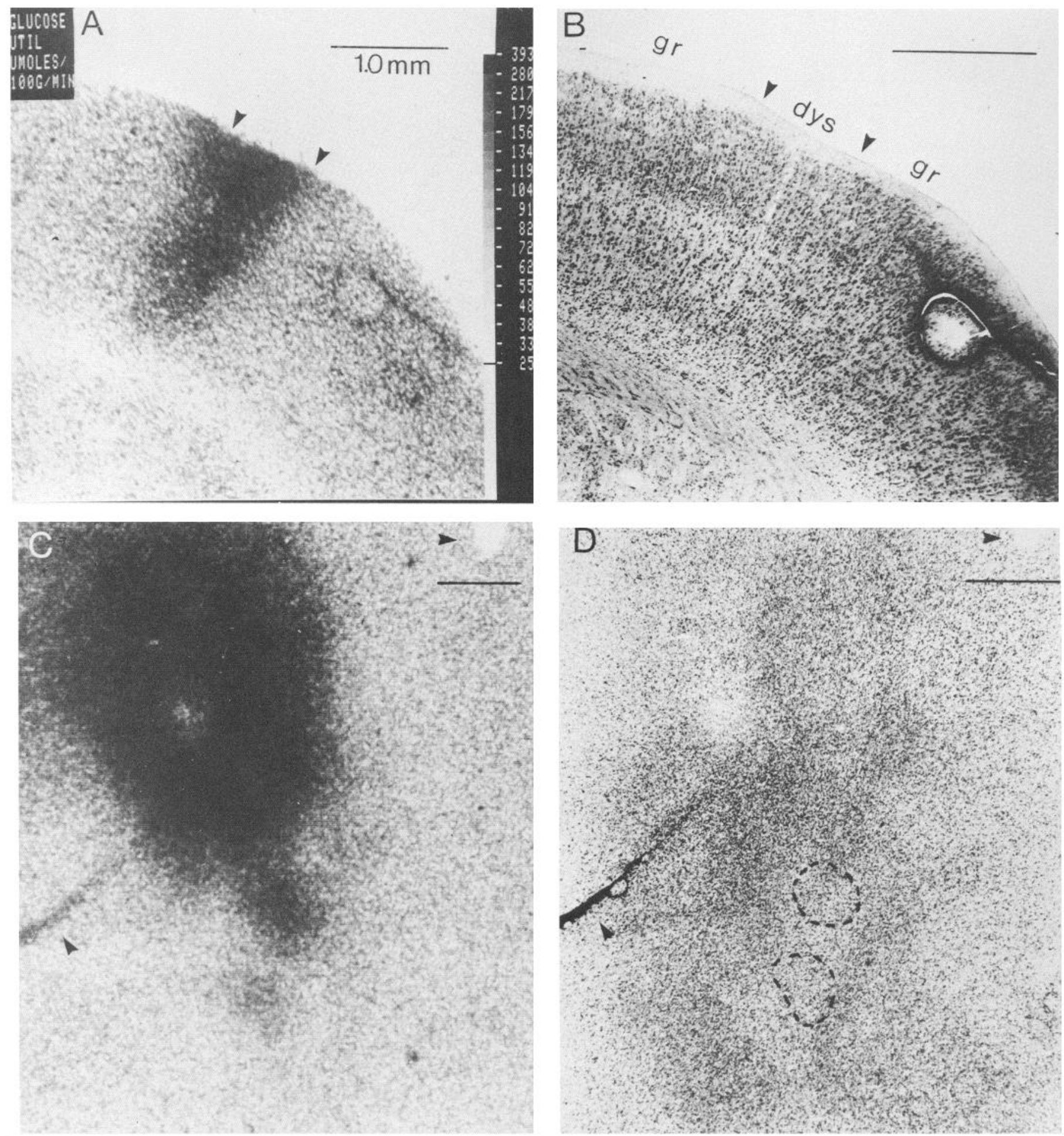

Figure 3. Metabolic columns in SI. A, Digitized autoradiogram through somatosensory cortex behind the stimulation focus. The pseudo-gray scale on the right indicates the rate of glucose utilization in the cortex. $B$, Thionin stain of the section used to produce the autoradiogram. Alignment of edges and cutting artifacts indicate that the column lies in a dysgranular zone (between arrows). $C$, Digitized autoradiogram of a horizontal section from a flattened hemisphere. The electrode track is at the border of the motor and the sensorimotor overlap zone. Note two columnar profiles cut in cross section beyond the posterior border of the stimulation focus. $D$, Thionin stain shows the dense cellularity of the granular fields. Overlapping the images by using tissue folds and blood vessels (arrows) reveals that the columns lie in the dysgranular zones. Scale bars, $1.0 \mathrm{~mm}$.

potential was unchanged, assuring effective stimulation. DG studies in these animals revealed the same pattern of activation in the cortex and subcortical sites that included the cerebellum (compare $D$ to $A$, Fig. 6). In contrast, there was only slight and inconsistent evidence of activation in the cuneate nucleus and the spinal cord (Fig. 6, $D-F$ ).

\section{Stimulation of forelimb sensory cortex}

To analyze forelimb sensory pathways, the electrode was placed in the posterior lateral part of the zone for high-amplitude evoked potentials, $0.5 \mathrm{~mm}$ anterior and $4.0 \mathrm{~mm}$ lateral to bregma (see topical map in Fig. 1). Animals were stimulated awake at 8.4 

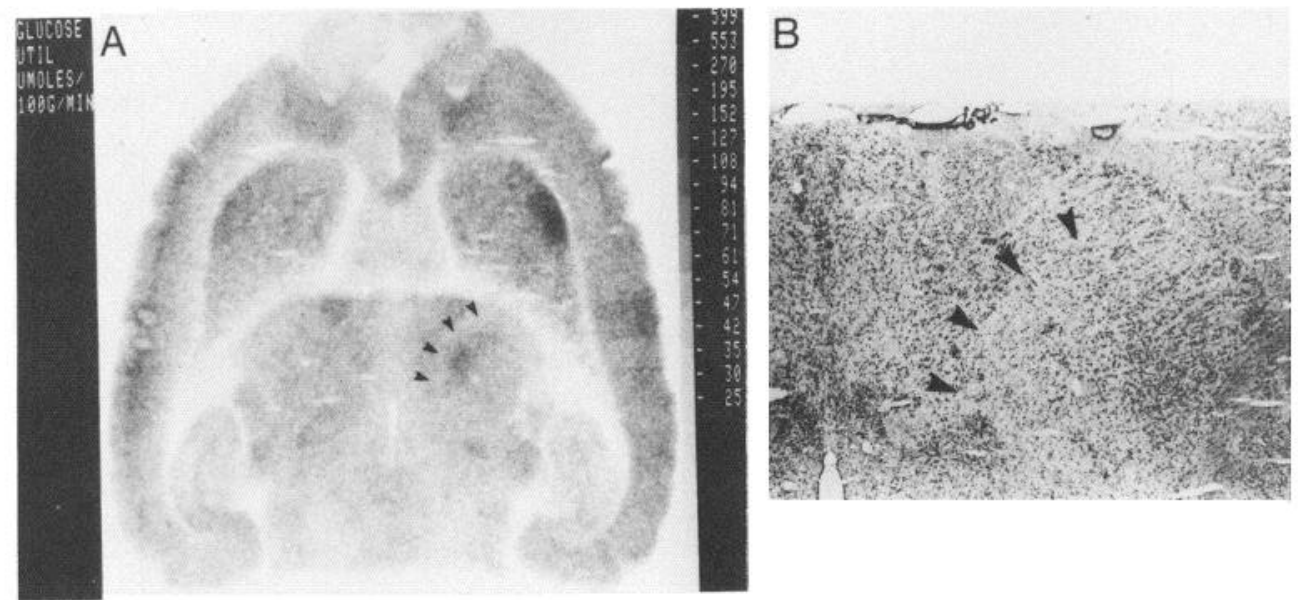

C
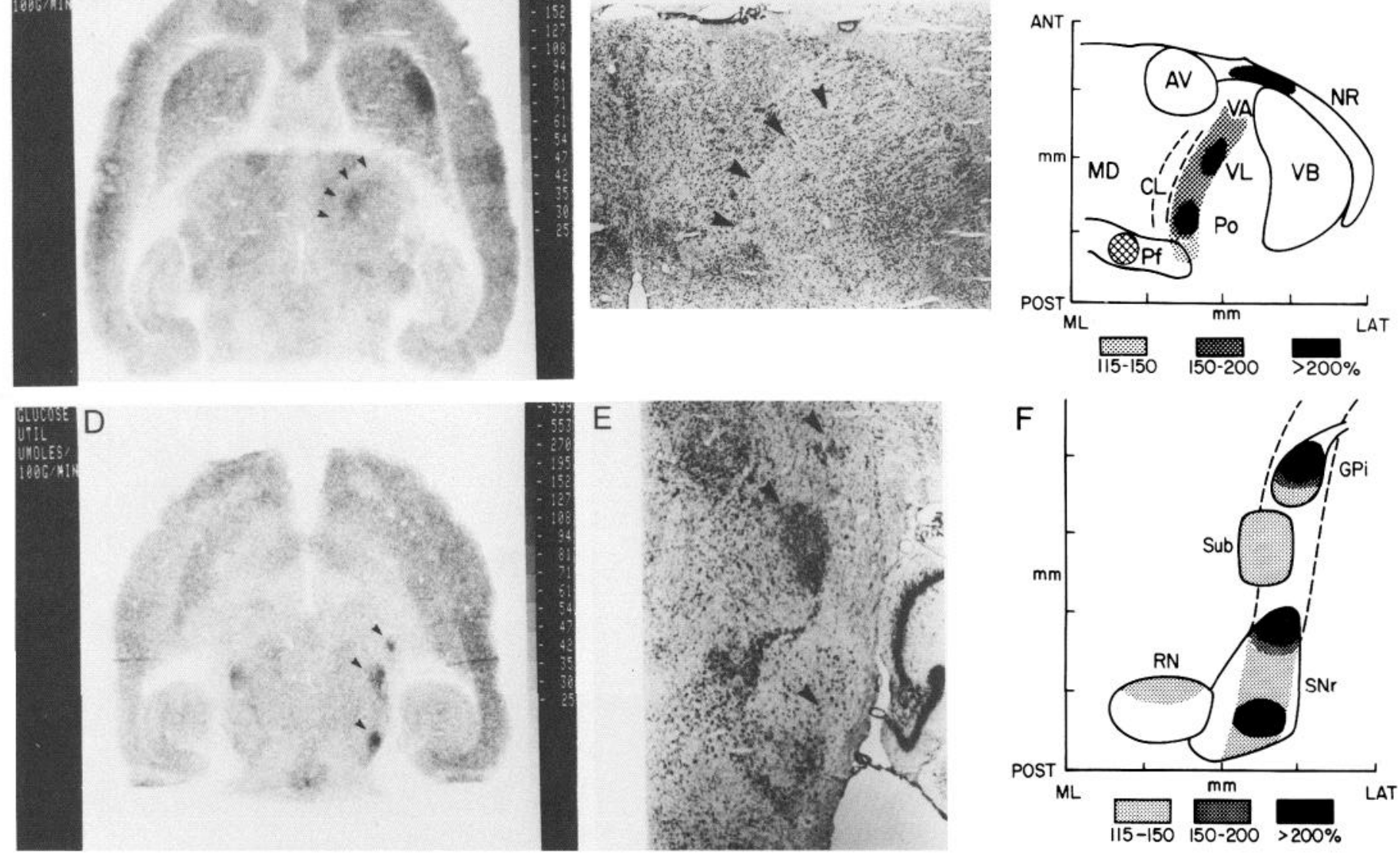

Figure 4. Metabolic changes in subcortical circuits. A, Digitized autoradiogram of a horizontal section through the dorsal thalamus of an awake animal stimulated in motor cortex at two trains/sec. There is up to a twofold increase in metabolism in the ipsilateral dorsolateral caudate and the dorsal thalamus (arrows). Note the increase in metabolism in SII in the ipsilateral hemisphere, but the relative depression of metabolic activity in layer IV in other fields compared with the normal pattern in the contralateral hemisphere. $B$, Thionin stain of the thalamus showing the site of metabolic activation in a dorsal corridor running through VA, VL, and Po (arrows). $C$, Summary of changes found in thalamus in animals stimulated awake at two trains/sec. The shading indicates the relative increase in metabolism compared with controls. $D$, Digitized autoradiogram through a ventral horizontal section. Metabolism is increased in ipsilateral globus pallidus interna, the subthalamic nucleus, and the substantia nigra, pars reticulata (arrows). E, Thionin stain showing sites of labeling (arrows). F, Summary composite from awake animals showing metabolic activation in the ventral, basal ganglia corridor. $A V$, anteroventral nucleus; $C L$, centrolateral nucleus; $G P i$, globus pallidus interna; $M D$, mediodorsal nucleus; $N R$, nucleus reticularis; $P f$, parafasicularis nucleus; $R N$, red nucleus; $S u b$, subthalamic nucleus; $S N r$, substantia nigra, pars reticulata; $V A$, ventral anterior nucleus; $V B$, ventrobasal complex; $V L$, ventral lateral nucleus.

$\mathrm{V}$, which represents the mean intensity used to induce movements from motor cortex. In this case there were no movements. Analysis of changes in cortex revealed activation beyond the stimulation site in ipsilateral SI, SII, and MI and contralateral SI.

Analysis of subcortical circuits in these cases revealed activation of basal ganglia, thalamus, midbrain, and cerebellum. Changes in basal ganglia were less intense than with stimulation of the forelimb motor zone. Activation in caudatoputamen was displaced posterior to the motor zone, but areas of activation in globus pallidus and substantia nigra showed some overlap with motor zones. There were areas of clear overlap in midbrain (deep mesencephalic nucleus and deep layers of superior colliculus) and the posterior lobules of cerebellum.

To provide a direct comparison between sensory and motor pathways in thalamus, one animal was stimulated with an electrode in the forelimb motor zone on the right side and in the sensory zone on the left side. Forelimb jerks occurred only on the side contralateral to the motor cortex electrode. Findings in this "double stimulation" case were representative of individual cases. Of note was the lack of overlap in the pattern of metabolic activation within thalamic nuclei (Fig. 7). Compared with motor stimulation, sensory cortex stimulation activated more posterior fields within nucleus reticularis and more lateral portions of dorsal thalamus in ventralis lateralis and the nucleus posterior (Fig. 7). On the sensory side there was no activation anterior to ventralis anterior or posterior to parafasicularis. There was intense activation of the ventral basal complex but none within the ventral medial nucleus or zona incerta.

\section{Metabolic response vs stimulus rate}

The effect of increasing stimulus rate on cerebral metabolism was studied in animals under light halothane anesthesia (Fig. 8). Several interesting features emerged. DG utilization at the stimulus site increased fourfold at low stimulation rates (30/ $\mathrm{min}$ ) and then leveled off. Autoradiograms of these animals were reexposed for short time periods $(4-24 \mathrm{hr})$ to be certain the plateau effect was not due to saturation of silver grains on the film by high tissue concentrations of radioactivity. This proved not to be the case, indicating a plateau of $4 \mu \mathrm{mol} / \mathrm{gm} / \mathrm{min}$ for the maximal metabolic rate for glucose in cortex. Cortical areas distant from the site of stimulation, e.g., ipsilateral columns in frontal cortex and contralateral motor cortex, showed a twofold increase in cerebral metabolism. A similar degree of activation 

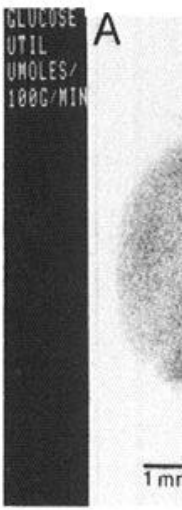

D
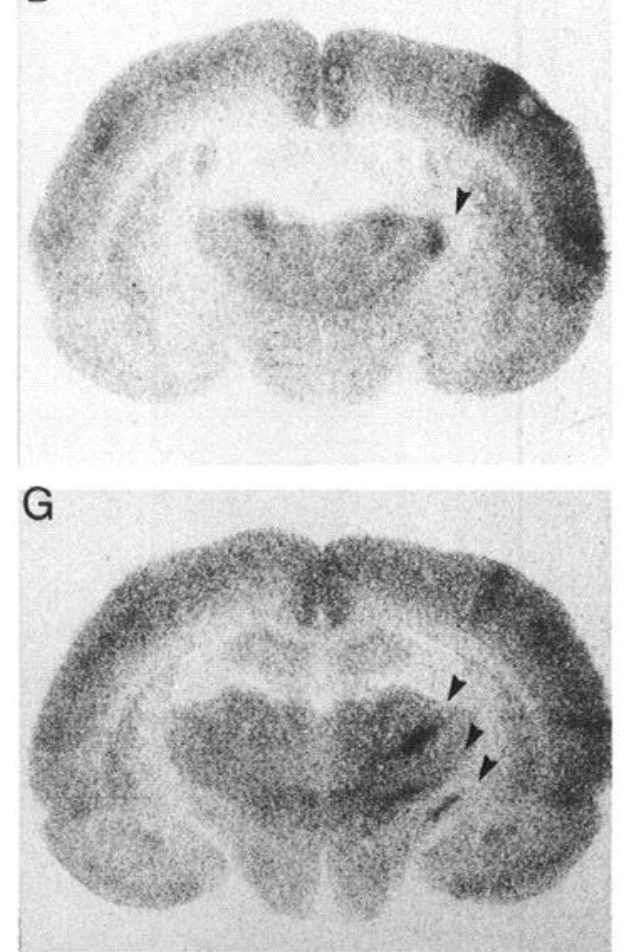

B

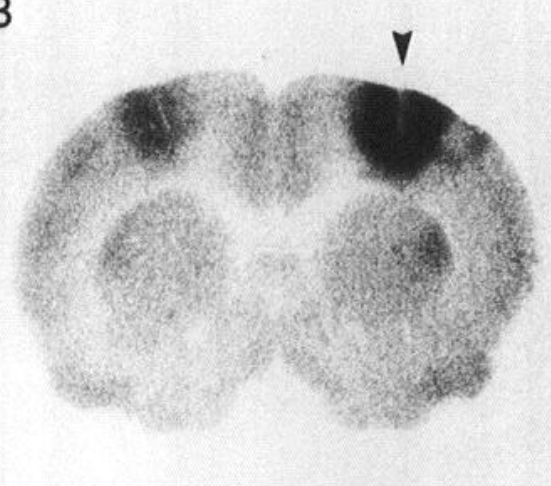

E

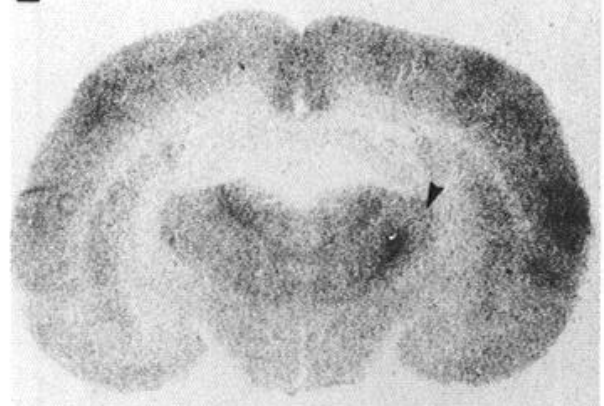

$\mathrm{H}$

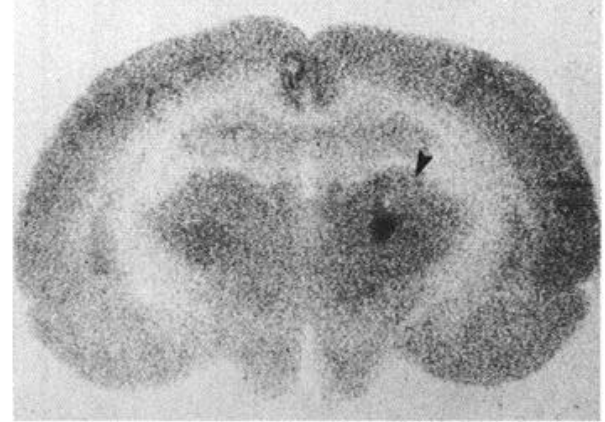

C

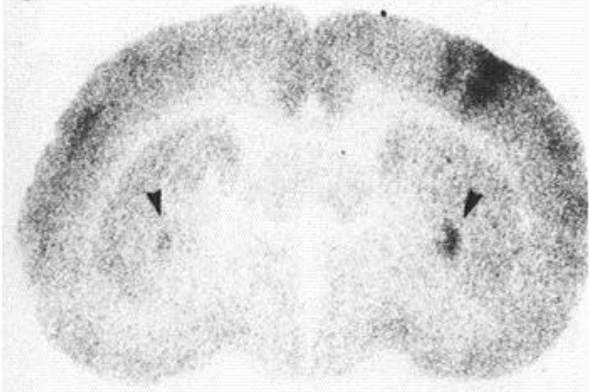

F

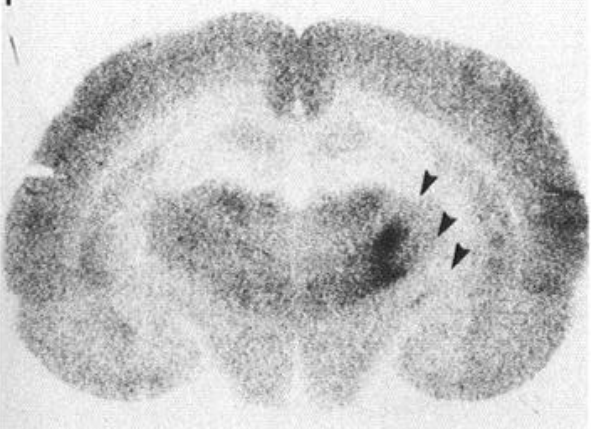

I

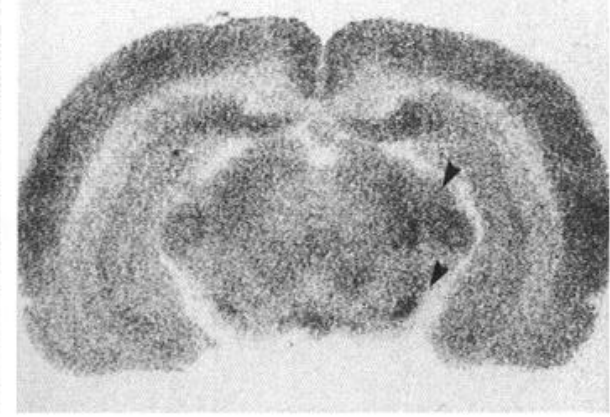

Figure 5. Metabolic activation of forelimb circuits from motor cortex stimulation at two trains/sec, awake. Sections are digitized autoradiograms, with the gray scale indicating the magnitude of glucose utilization $(\mu \mathrm{mol} / 100 \mathrm{gm} / \mathrm{min})$ for all sections. $A$, Anterior section showing distant activation in MII. B, Stimulation focus (arrow = electrode track) with activation in contralateral MI, and the dorsolateral caudate, ipsilateral + contralateral. The stimulation focus extends posterolateral into the granular overlap zone. $C$, Columnar profiles in SI. Activation in globus pallidus externa, ipsilateral + contralateral. $D$, Nucleus reticularis. $E$, Ventralis anterior-ventralis lateralis. $F$, Ventralis lateralis, the ventrobasal complex and globus pallidus interna. $G$, Ventralis lateralis, ventral medial nucleus (faint), zona incerta, and globus pallidus interna. $H$, Posterior thalamic nucleus. $I$, Deep mesencephalic nucleus (ipsilateral, faint) and substantia nigra, pars reticulata, ipsilateral + contralateral.

occurred in the sector of corpus callosum connecting the stimulation site to the contralateral motor cortex. This suggests a similar degree of metabolic demand was placed on distant cortical fields and the fiber pathways to them.

Beyond the stimulation site the greatest relative increase in metabolism occurred in basal ganglia, primarily within globus pallidus externa, globus pallidus interna, and the substantia nigra, pars reticulata (Fig. 8, second row). With increasing frequency of stimulation there was a progressive and linear increase in glucose utilization in these sites up to three- to fourfold times control. By contrast, metabolism in thalamus increased only slightly compared with cortex and basal ganglia (Fig. 8, third row). This weak response in thalamus was partly due to the effect of anesthesia. When the metabolic responses of halothaneanesthetized animals were compared with those of awake animals, there was evidence of depression in all sites (Table 2), but the greatest relative depression seemed to be in ventralis lateralis ( $25 \%$ of awake) and the nucleus posterior (no response).

\section{Anatomic pathways}

\section{Projections from motor and sensory forelimb cortex}

In order to compare patterns of metabolic activation with patterns of anatomic pathways, two approaches were used. First, small volumes of ${ }^{3} \mathrm{H}$-proline were injected to trace projections from motor and sensory subdivisions of forelimb cortex. Results of these studies indicated the precise boundaries of subcortical fields in caudatoputamen and thalamus (Fig. 9). These data were also helpful in analyzing terminal fields in a second series of animals where ${ }^{14} \mathrm{C}$-proline, -alanine, or -leucine injections were used with quantitative film autoradiography (Fig. 10). The size and optical density of each terminal field was measured directly 

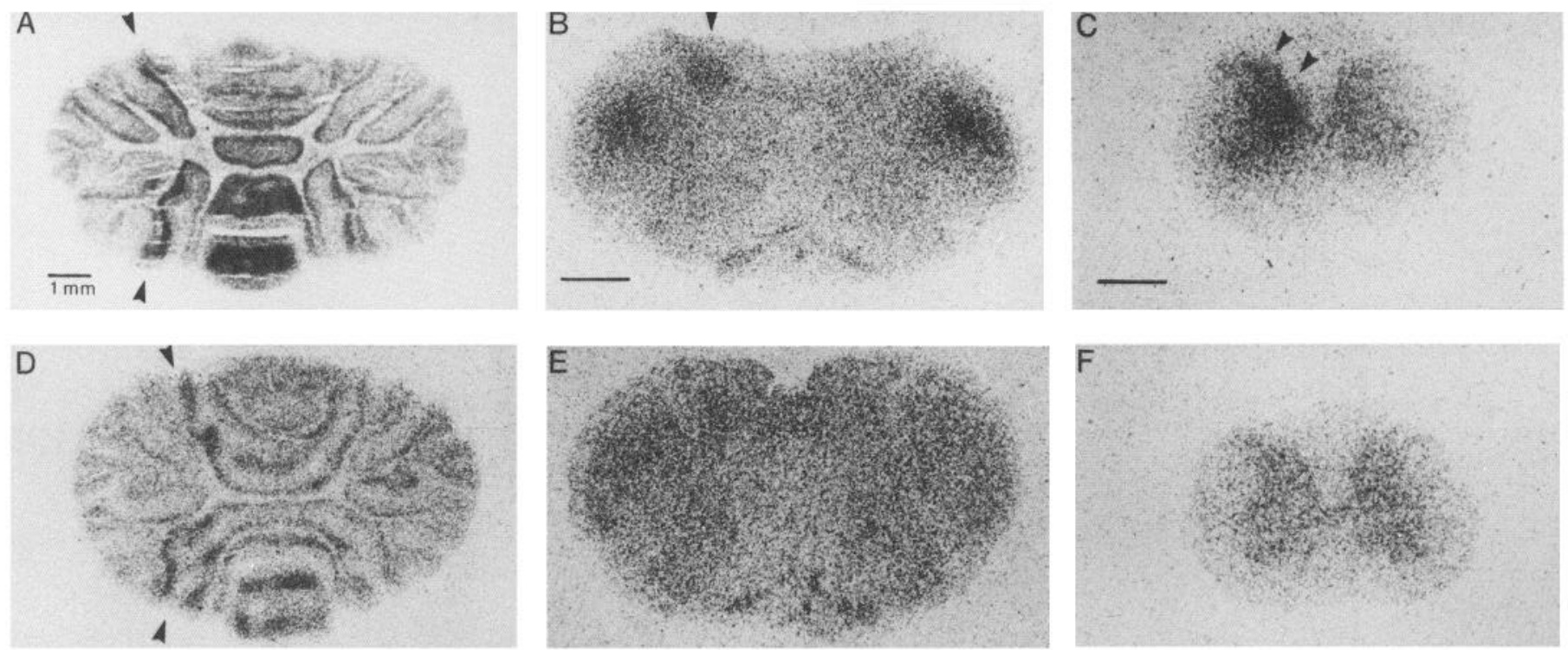

Figure 6. Activation of cerebellum, medulla, and spinal cord during motor cortex stimulation, representative autoradiograms. Top panel: $A-C$, Awake animal. Bottom panel: $D-F$, Awake animal with forelimb deafferentation (see text). $A$, Horizontal section of cerebellum showing increased activity in contralateral anterior lobules (V and simplex) and posterior lobules (paramedian and copula pyramis). $B$, Cuneate nucleus (arrow). $C$, Cervical spinal cord, activation of dorsal horn. $D$, Forelimb deafferented cerebellum showing same topographical pattern of metabolic activation. $E$, No activation of deafferented cuneate or $F$, spinal cord.

from the film. The amount of radioactivity in each site was then determined by interpolation from the optical densities of adjacent radioactive standards. Of the total amount of radioactivity in the forebrain (e.g., animal 9/53 \#1, Fig. 11), 83.4\% remained in the injection focus, $9.3 \%$ was in distant cortical fields, and $7.3 \%$ was subcortical in caudate, thalamus, and midbrain (pons, medulla, and cord not analyzed).

Cortical projections beyond the forelimb motor zone went predominately to ipsilateral SI (47\%) and contralateral MI (43\%), with considerably less to ipsilateral SII $(8.3 \%)$ or contralateral SI $(1.4 \%)$. By comparison with the strong MI to SI connection, injections into forelimb sensory cortex resulted in weak projections to MI. Most SI projections were to ipsilateral SII and contralateral SI (Fig. 11).

The greatest amount of subcortical projection from both motor and sensory cortex was into thalamus, representing an average of 67 and $88 \%$ of the total subcortical projection of radioactivity, respectively (Table 3 ). With motor cortex injections, the terminal fields in dorsal thalamus ran contiguously from ventralis anterior through ventralis lateralis into the posterior thalamic nucleus. Medially this corridor included aspects of the central lateral nucleus and parafasicularis. With injections into sensory zones this corridor began in posterior aspects of ventralis lateralis or the nucleus posterior. We found that exact boundaries between these nuclei were indistinct. A small amount of label was found medially in the central lateral and parafasicularis nuclei. Compared with motor projections, there were no forelimb sensory projections into anterior dorsal thalamus, the ventral medial nucleus, or the zona incerta. Both cortical zones projected to posteriolateral zones of the deep layers of superior collicus and the deep mesencephalic nucleus in midbrain.

\section{Anatomical pathways vs functional anatomy}

When the two different methods of anatomical mapping are compared, several features emerge. First, stimulation of cortex increases glucose utilization in distant cortical sites in a pattern that primarily represents first-order connections to those sites. This can be seen in the cortex by comparing the pattern of corticocortical anatomical connections (Fig. 11) with the pattern of cortical metabolism resulting from cortical stimulation (Fig. 2). Subcortical labeling can be compared by contrasting figures of metabolic activation (Figs. 4 and 5) with anatomic pathway labeling (Figs. 9 and 10). Second, the magnitude of change in metabolism within different subcortical terminal fields in response to stimulation did not correlate well with either the

Table 2. Mean increase in glucose utilization with stimulation of motor cortex at 120 trains/min (magnitude of increase above control, $\mu \mathrm{mol} / \mathrm{gm} / \mathrm{min}$ )

\begin{tabular}{lll} 
& $\begin{array}{l}\text { Anesthetized } \\
(n=3)\end{array}$ & $\begin{array}{l}\text { Awake } \\
(n=1)\end{array}$ \\
\hline Cortex & & \\
$\quad$ Stimulation focus & 2.80 & 3.96 \\
$\quad$ Anterior columns & 1.26 & 2.83 \\
Corpus callosum & 0.51 & 0.63 \\
Contralateral cortex & 0.95 & 2.18 \\
Basal Ganglia & & \\
$\quad$ Dorsolateral caudate & 1.02 & 1.68 \\
Globus pallidus externa & 1.29 & 2.51 \\
Globus pallidus interna & 0.43 & 1.53 \\
$\quad$ Subthalamic nucleus & 0.15 & 0.59 \\
$\quad$ Substantia nigra & 0.62 & 2.04 \\
Thalamus & & \\
$\quad$ Nucleus reticularis & 0.30 & 0.59 \\
Ventralis lateralis & 0.26 & 1.02 \\
$\quad$ Nucleus posterior & - & 0.59 \\
Parafasicularis & 0.20 & 0.37 \\
Midbrain & & \\
$\quad$ Deep superior colliculus & & \\
Deep mesencephalic nucleus & 0.15 & 0.42 \\
Red nucleus & 0.11 & 0.40 \\
& - & 0.14 \\
\hline
\end{tabular}



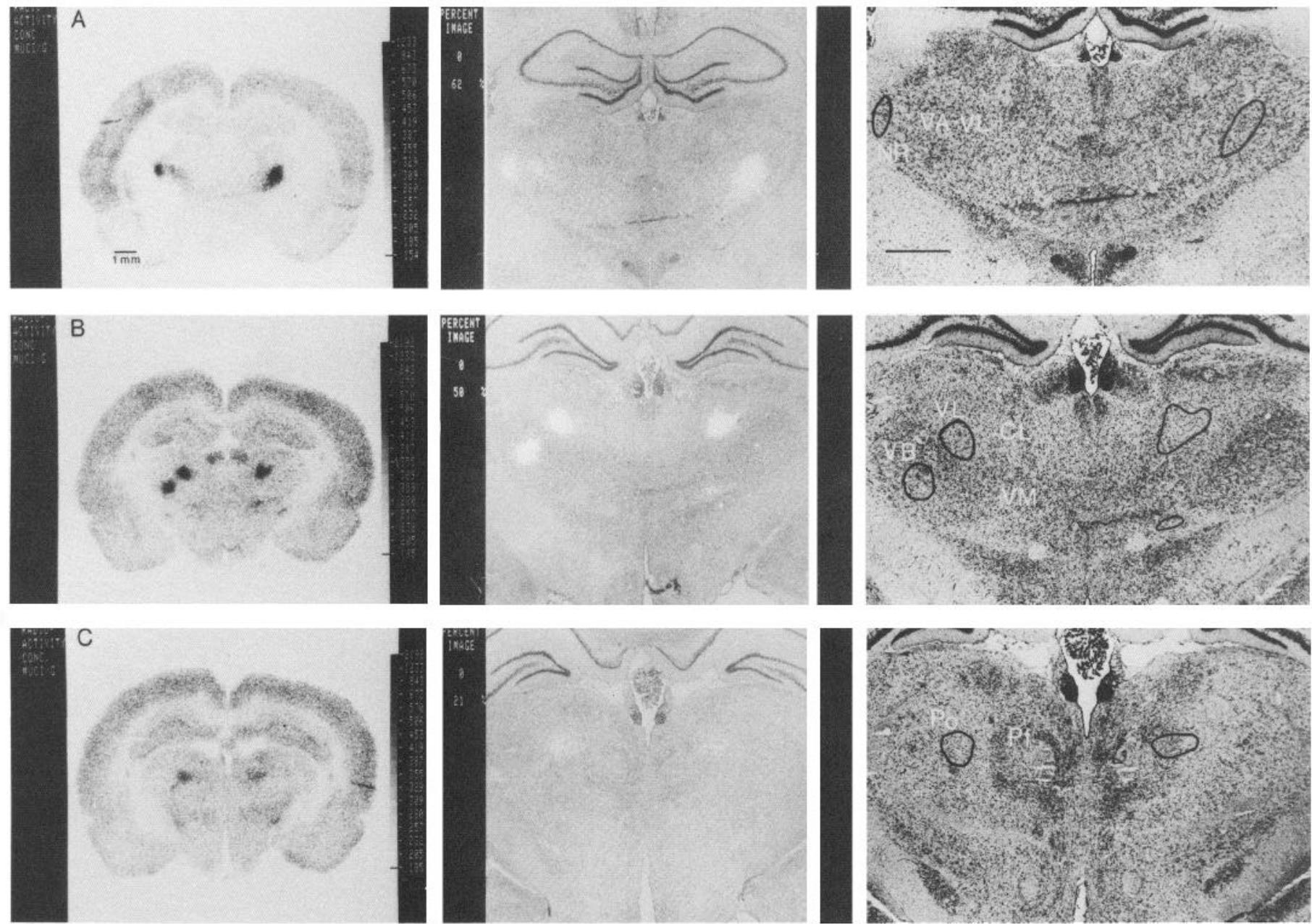

Figure 7. Comparison of thalamic activation from forelimb sensory cortex (left side of figures) with activation from forelimb motor cortex (right side of figures). The rows labeled $A, B$, and $C$ represent coronal sections through the anterior, mid-, and posterior thalamus. The first section in each row shows the digitized autoradiogram with the pseudo-gray scale of metabolic rates for glucose utilization indicated on the right. The second section shows an enlargement of the thalamus where the metabolic densities and the thionin sections were aligned by computerized image analysis techniques. The metabolic values were selected by a windowing program to illustrate the highest values for each section. These were reversed to white for ease of viewing. The percent of each composite image that is devoted to the thionin-stained background is illustrated on the left. The third figure in each row shows the thionin-stained section with the contours of the metabolic profiles superimposed.

density or total amount of anatomic projection into the field. For example, compared with the caudate nucleus, the ventral lateral nucleus showed a greater anatomic density of motor cortex projections, but a weaker metabolic response to motor cortex stimulation in either awake or anesthetized animals. Finally, the overall pattern of metabolic response to cortex stimulation reflects polysynaptic connections as well. This was seen dramatically in the metabolic response of basal ganglia activated from second-order projections from caudatoputamen, as well as in the influence of the moving limb and sensory feedback on metabolism in the cuneate nucleus and the spinal cord. These latter findings are explored in more detail in the subsequent paper (Santori et al., 1986).

\section{Discussion}

\section{Technical considerations}

This study confirms and extends earlier observations that the sites and intensity of the cerebral metabolic response to electrode stimulation depend on the configuration and frequency of the stimulus (Collins et al., 1980; Sharp, 1984; Sharp and Evans, 1982), and the use of anesthesia (Roberts, 1980; Savaki et al., 1983a, b). Repetitive stimulation with short-duration, high-frequency trains $(500 \mathrm{~Hz}, 20 \mathrm{msec})$ proved to be most efficacious for inducing discrete forelimb movements from motor cortex with concomitant activation of DG metabolism. The stimuli used in this study likely activated both axons and neurons in the field between the anode in layer $\mathrm{V}$ and the cathode in layer II-III (Jankowska et al., 1975; Ranck, 1975). From studies of the volume and pattern of metabolic change around the stimulating electrode (see also Collins, 1980), we estimate that the minimal field of activation is $0.7-1.0 \mathrm{~mm}$ in diameter using these methods. For this reason, as well as limits of resolution imposed by ${ }^{14} \mathrm{C}$ isotopes and film autoradiography, the anatomic data of this study is relevant to histological fields rather than to local circuits or cells within such fields.

The size of the focus and the appearance of metabolic change in distant sites were dependent on stimulus rate. Although cortical metabolism was activated at relatively low rates of stimulation (once per $4 \mathrm{sec}$ using trains of $500 \mathrm{~Hz}$ for $20 \mathrm{msec}$ ), metabolic change in first-order subcortical sites remained inconsistent below stimulation rates of once per second. In terms of using these techniques for metabolic mapping of functional or behavioral activity, these rates may seem high. In terms of 


\begin{tabular}{|c|c|c|c|c|}
\hline & \multicolumn{2}{|c|}{$\begin{array}{l}\text { From motor } \\
\text { zones }\end{array}$} & \multicolumn{2}{|c|}{$\begin{array}{l}\text { From scnsory } \\
\text { zones }\end{array}$} \\
\hline & $\begin{array}{l}2 / 153 \\
\# 3\end{array}$ & $\begin{array}{l}9 / 53 \\
\# 1\end{array}$ & $\begin{array}{l}9 / 3 \\
\# 2 \\
\end{array}$ & $\begin{array}{l}9 / 53 \\
\# 2 \\
\end{array}$ \\
\hline \multicolumn{5}{|l|}{ Caudate } \\
\hline Ipsilateral & 32.1 & 29.0 & 10.1 & 14.2 \\
\hline Contralateral & 2.9 & 2.8 & 0 & 0 \\
\hline \multicolumn{5}{|l|}{ Thalamus } \\
\hline Nucleus reticularis & 3.4 & 3.1 & 8.3 & 8.9 \\
\hline Ventralis lateralis & 45.4 & 39.5 & 0 & 0 \\
\hline Central lateral & 7.5 & 10.6 & 3.6 & 1.4 \\
\hline Nucleus posterior & 3.3 & 2.1 & 18.0 & 8.8 \\
\hline Parafascicularis & 0.8 & 0.5 & 1.4 & 0 \\
\hline Ventral medial & 2.1 & 4.4 & 0 & 0 \\
\hline Ventral basal & 0 & 0 & 58.3 & 66.4 \\
\hline \multicolumn{5}{|l|}{ Midbrain } \\
\hline Deep mesencephalic nucleus & 2.1 & 2.6 & 0.5 & 0.2 \\
\hline
\end{tabular}

the energy metabolism of nerve tissue, however, they may be low. At this rate the stimulus occupies only $20 \mathrm{msec}$ of every second-i.e., at least $90 \%$ of the time the stimulated pathways are probably near a resting level of physiological activity. Although the metabolic response to stimulation outlasts the stimulus (Lothman et al., 1975), this is likely to be prolonged only in the stimulus site, where there would be depolarization of nonspecific elements such as glia and neighboring interneurons. As the DG technique proceeds for $40 \mathrm{~min}$, it temporally integrates periods of stimulation and rest. Although a denser pattern of distant metabolic labeling occurs with higher rates of stimulation, the upper limit is probably $3 / \mathrm{sec}$ with cortical stimulation. Above this rate seizures occur (our study) or refractoriness develops (Sharp, 1984). High rates of stimulation have been used with intermittent periods of rest to enhance labeling (Roberts, 1980; Sharp, 1984; Sharp and Evans, 1982), but the interpretation of findings relevant to steady-state physiology is problematical. Similarly, although light anesthesia allows higher stimulus rates, there can be differential anesthetic effects on different structures (Savaki et al., 1983a, b). In this study we found halothane caused a relatively greater depression of corticothalamic circuits than basal ganglia circuits.

\section{Metabolic anatomy of stimulated forelimb movement}

In general, our findings support many of the observations of Sharp (1984) and Sharp and Ryan (1984) on the metabolic activation of neuroanatomic sites with stimulation of forelimb motor cortex. Their studies focused on the correlation between the appearance of metabolic changes with known anatomic pathways. Several points merit discussion in comparing our results with their findings. First, we were unable to document statistically significant metabolic changes in several subcortical sites found by these workers. These included the subthalamic nucleus, red nucleus, basal pontine nuclei, and deep cerebellar nuclei. Part of the discrepancy is technical. We used approximately half their rate of stimulation. In addition, we measured each activated field and calculated the mean change rather than report the greatest value. Although these sites were below the sensitivity of our present study, we have found that they show consistent metabolic activation during focal seizures in forelimb neocortex (Collins, 1978b; Collins et al., 1976).

Second, we found a homogenous pattern of metabolism in
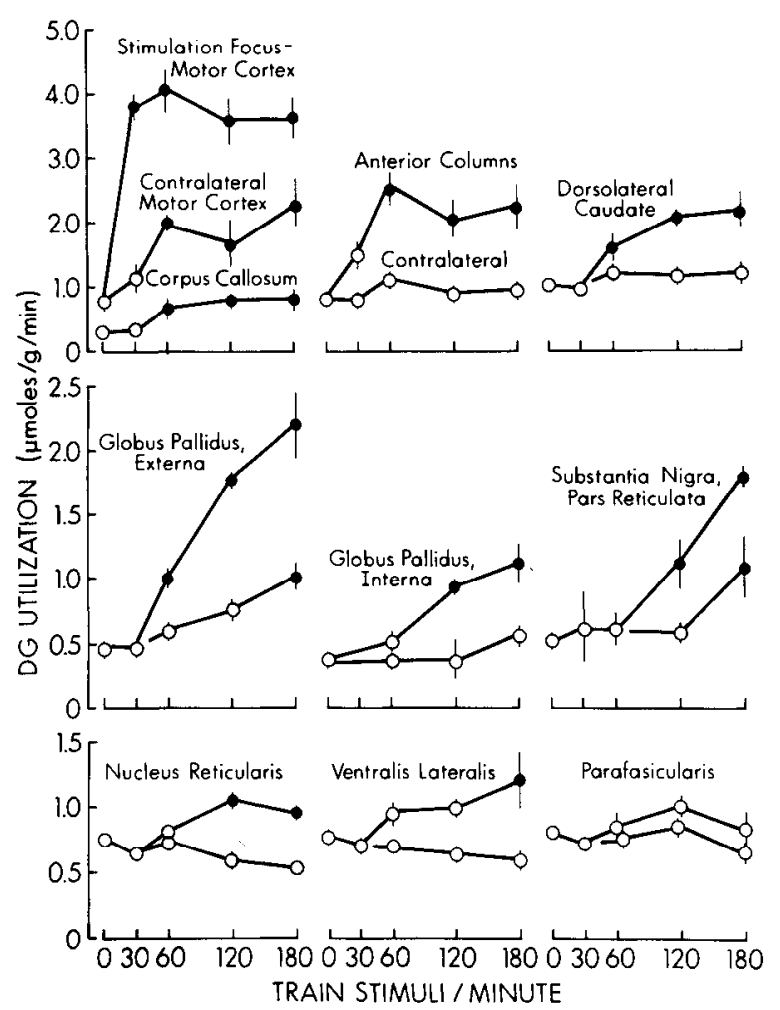

Figure 8. Stimulation of forelimb motor cortex. Metabolic response to DG in pathways as a function of stimulus rate $(500 \mathrm{~Hz}, 20 \mathrm{msec}$ train stimulus). The top trace in each graph represents ipsilateral sites, the bottom trace, contralateral sites. Vertical bars represent SEM $(n=$ 3-5). Filled symbols represent statistical significance vs unstimulated controls. $P=0.05$ (Duncan's multiple range).

the cerebellar granule cell layer in response to motor cortex stimulation rather than a patch-like pattern of activation (Sharp and Ryan, 1984). In addition, removal of sensory feedback by cutting the brachial plexus or, conversely, direct stimulation of forelimb muscles to produce peripheral movement (Der et al., 1983; Santori et al., 1986) failed to activate multiple discrete patches. Stimulation of adjacent points in sensory cortex has been found to activate contiguous zones in the cerebellar granule cell layer (Bower et al., 1981). In addition, our stimulation procedures probably activated proprioceptive systems more than the extereoceptive systems of forelimb cutaneous fields that have been mapped with microstimulation (Joseph et al., 1978; Shambes et al., 1978). We remain uncertain as to the cause of metabolic patches found by Sharp and Ryan (1982), but we suspect it may be related to high-intensity stimulation, since we have seen this cerebellar pattern with focal motor seizures (Collins et al., 1976, Fig. 2).

Finally, our results indicate that the forelimb portion of the ventral-basal nucleus of thalamus is activated from the granular portion of forelimb motor cortex. Stimulation foci that did not encompass the overlap zone did not activatc VB. This is consistent with known corticothalamic relationships in rat (Donoghue et al., 1979; Wise and Jones, 1977) and with the pathway tracing experiments reported here. In addition, stimulation of adjacent granular sensory cortex that included the overlap zone activatcd portions of dorsal thalamus posterior and lateral to the corridor activated from motor cortex. These observations support findings of others that the overlap zone has input-output cortical and subcortical connections partially distinct from pure motor and pure sensory forelimb cortex (Chapin and Woodward, 1982; Donoghue and Wise, 1982; Sanderson et al., 1984; Welker et al., 1984; Wise and Jones, 1977). 

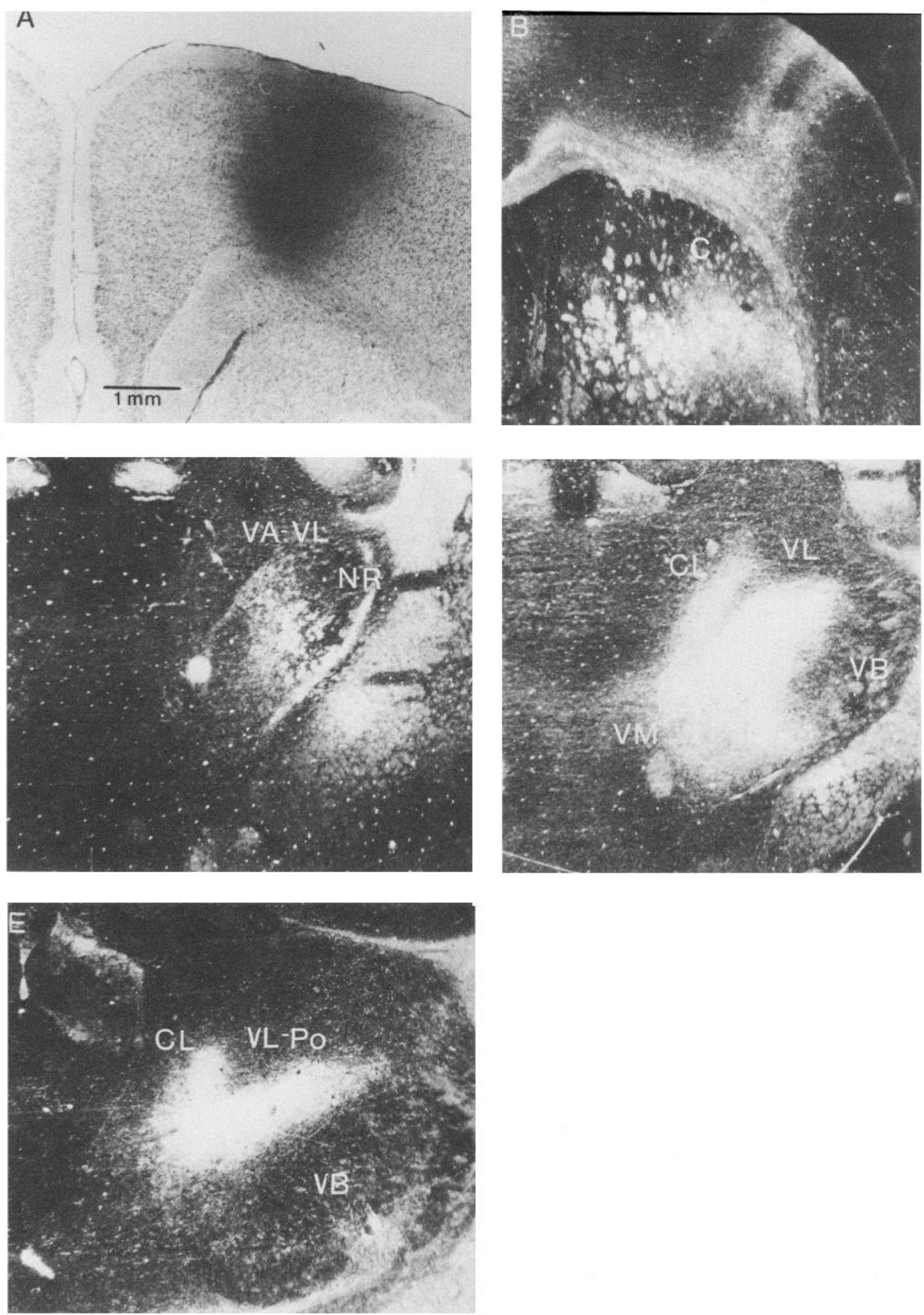

Figure 9. Forelimb motor pathways, ${ }^{3} \mathrm{H}$-amino acid axoplasmic transport autoradiography, representative sections of forebrain pathways. $A$, Bright-field view of an injection site in the agranular motor cortex. $B$, Dark-field view of terminal fields in SI cortex, dorsolateral caudate, and fiber bundles of passage in medial caudate. The bright-field view of cortex revealed that columnar profiles occupied a dysgranular zone (see Fig. 3). $C$, Anterior thalamus with labeling in ventralis anterior-ventralis lateralis $(V A-V L)$, nucleus reticularis $(N R)$, and internal capsule. $D$, Midthalamus with labeling in the central lateral nucleus $(C L)$, and the main body of ventralis lateralis $(V L)$ with contiguous fields in the ventromedial nucleus $(V M) . E$, Midposterior thalamus with labeling in zones that overlap the central lateral nucleus and ventralis lateralis-nucleus posterior $(V L-P o)$. 

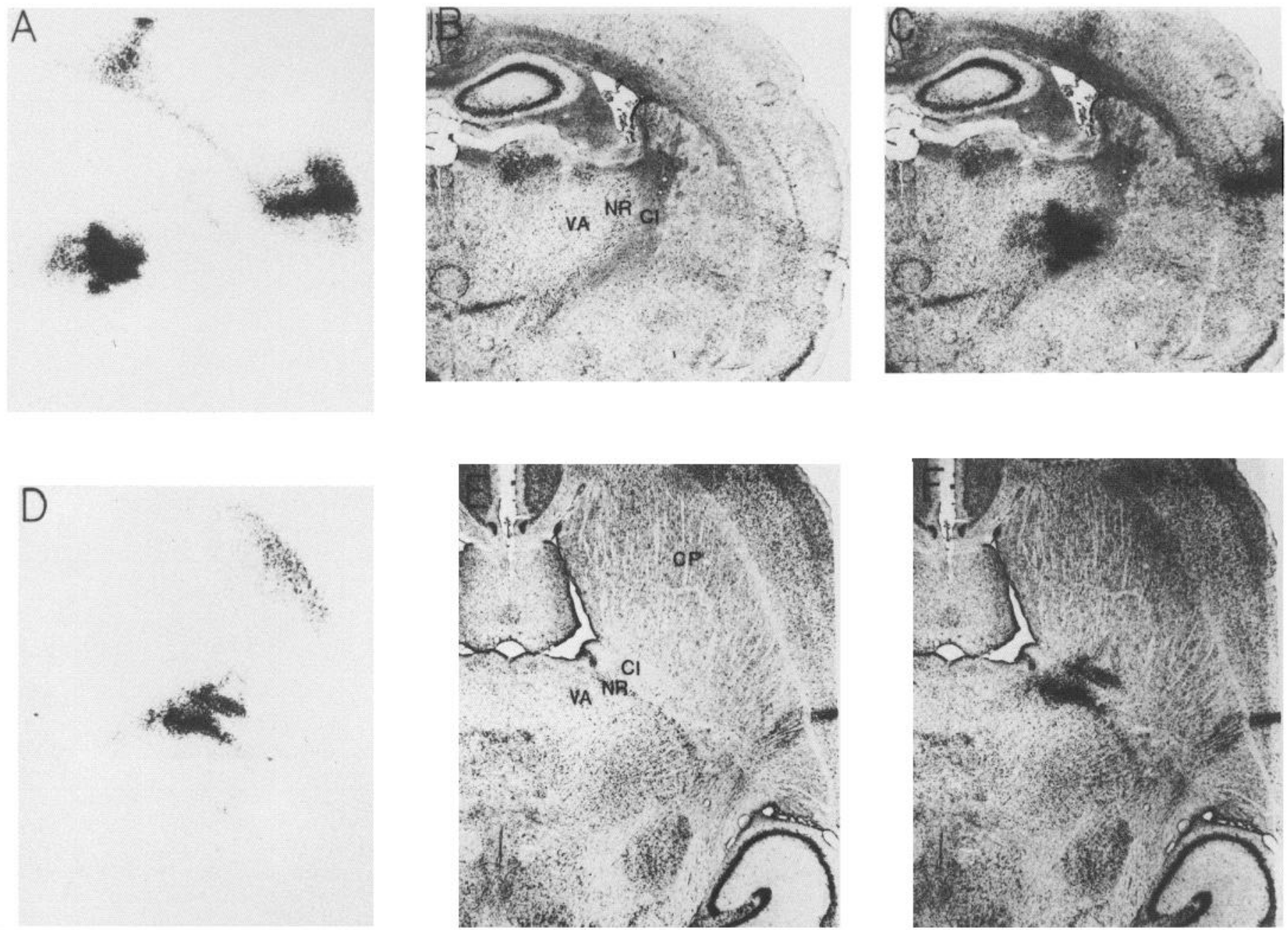

Figure 10. Film autoradiography of motor pathways using ${ }^{14} \mathrm{C}$-amino acids, representative sections. Top panel, Coronal section. $A$, Autoradiographic image used to measure density and area of terminal fields. Serial sections were analyzed to compute total amount of isotope in each site (see Methods). $B$, Thionin stain. $C$, Composite overlap used to confirm sites of labeling. Bottom panel, Horizontal section through ventral anterior thalamus. Calculations of terminal field labeling were done in two planes for confirmation. $D$, Autoradiogram. $E$, Thionin stain. $F$, Composite overlap.

\section{Metabolic anatomy vs pathway tracing}

Changes in cortical metabolism in response to cortical stimulation occurred in patterns primarily reflecting first-order corticocortical connections (Collins, 1980). Although there was variability between animals when details of pathway or metabolic maps were compared, the general pattern of topographic change was similar. The problems of topographic variations among animals in response to cortical stimulation have been noted and discussed (Donoghue and Wise, 1982; Sanderson et al., 1984). We found no convincing evidence for activation of second-order cortical projections. For example, activation of SI from an MI electrode failed to activate corticofugal projections beyond SI, such as the VB complex. In addition, activation into contralateral motor cortex was never relayed through its projection system into dorsal thalamus even at high rates and intensities of stimulation. For this reason we regard the metabolic activation of contralateral basal ganglia from motor cortex as a reflection of activity projecting in first-order crossed corticostriate pathways (Webster, 1961) rather than as evidence of inputoutput activity through contralateral motor cortex.

The major subcortical projection from forelimb motor cortex was to dorsal thalamus. Terminal fields were joined contig- uously into a corridor spanning traditional histological divisions of ventralis anterior, ventralis lateralis, and the posterior thalamic nucleus. There was overlap of portions of the ventral medial nucleus, central lateral nucleus, and parafasicularis. The corridor was somewhat narrower in pathway studies than metabolic mapping studies. Glucose changes here would probably reflect in part physiological activity "feeding back" toward motor cortex from polysynaptic projections through globus pallidus (Carter and Fibiger, 1978), substantia nigra (Beckstead et al., 1979; Faull and Carman, 1968) and cerebellum (Faull and Carman, 1978). This dorsal thalamic corridor undoubtedly represents a major site for integration of motor activity. Strong reciprocal connections with thalamus suggests motor cortex continuously influences incoming activity here as it simultaneously projects toward final common pathways in spinal cord.

Activation of dorsolateral caudatoputamen from motor cortex resulted pari passu in activation of globus pallidus and substantia nigra. Quantitative metabolic measurements suggested that this "ventral corridor" responded as a functional unit, with all sites here increasing in parallel with increasing rates of stimulation. Previous workers have drawn attention to the structural and functional similarities of globus pallidus interna and sub- 

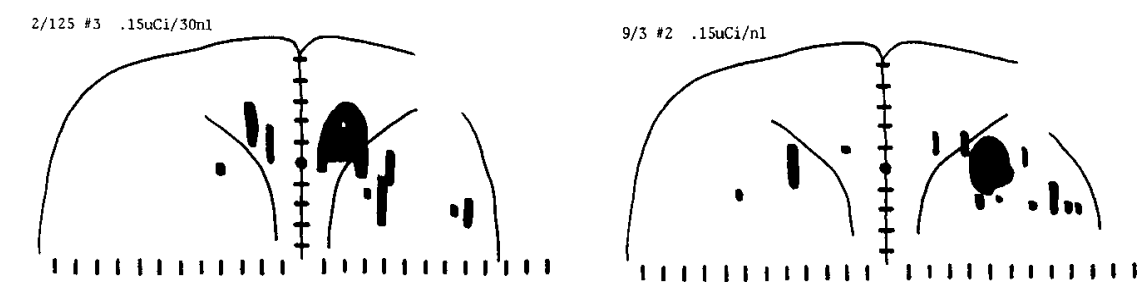

$9 / 53 \# 1$.3uCi $/ 50 \mathrm{ml}$

Figure 11. Corticocortical pathways from forelimb neocortex were reconstructed from coronal sections of composite autoradiographs and thionin-stained sections. This allowed for topographic localization and quantitative measurement of radioactivity in each terminal field (see text). Compare with Figure 2.
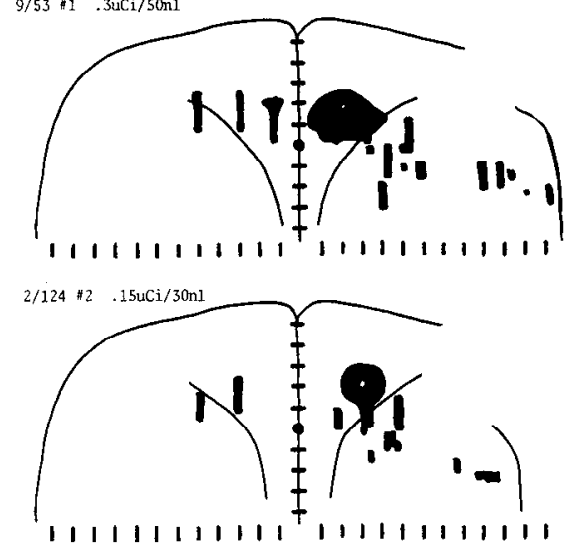
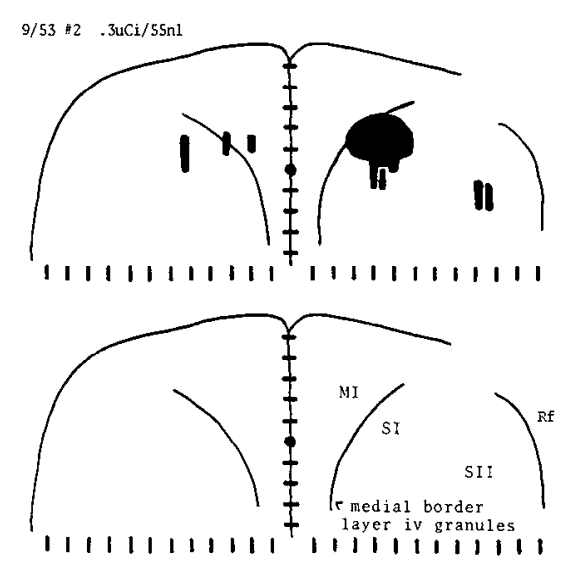

stantia nigra, pars reticulata (DeLong and Georgopoulos, 1981). In our studies there was activation of three sites among the cells constituting these nuclei, but at least part of the separation could be attributed to interspersed fibers of the internal capsule.

Sites of metabolic activation in striatum and thalamus were displaced with movement of the cortical focus across cytoarchitectural boundaries. In this study, activation within thalamus was different with stimulation of motor vs sensory forelimb cortex. This finding and previous DG mapping studies (Collins, 1978b; Collins and Caston, 1979; Collins and Divac, 1984; Divac and Dimer, 1980) support evidence that "topographic homologies" are preserved in projections through basal ganglia and thalamic circuits (for recent reviews, see DeLong and Georgopolous, 1981; Penney and Young, 1983).

\section{Physiologic dose vs metabolic response}

There was a complex relationship between stimulus frequency and metabolic response. The magnitude of the response quickly reached a ceiling in the stimulus focus and leveled off in corticocortical projection sites at one stimulus/sec. There was little further increase in metabolism between one and three stimuli/ $\mathrm{sec}$. By contrast, there was a progressive increase in metabolism in subcortical sites over the same range. This was marked in second-order sites in basal ganglia, where the relative increase was even greater than first-order projection sites.

The interpretation of this pattern of response is not straightforward. In general, most workers agree that glucose utilization increases in stimulated sites in response to energy needs for restoring membrane ion homeostasis (Collins, 1978a; Mata et al., 1980; Schwartz and Gainer, 1977; for review, see Sokoloff, 1984). DG changes are usually greatest in neuropil, where small increases in cation flux can result in large changes in ion concentrations inside small axon terminals and dendrites (Hurlbut, 1970). In general, a dark autoradiographic density signifies an area of increased ion pumping and secondarily suggests that afferent pathways into this area have increased their rate of firing. There may or may not be a relationship between metabolism and rates of cell discharge within the area of change itself (Auker et al., 1983; Schoppmann and Stryker, 1981; Theurich et al., 1984). Furthermore, changes in metabolism give no information about whether the afferent cell firing is excitatory or inhibitory. The increase in metabolism in globus pallidus and substantia nigra found in this study could reflect an increase in firing within striatofugal GABAergic inhibitory projections (Nagy et al., 1978; Somogyi et al., 1981; Yoshida et al., 1972). Hence, this increase in metabolism may actually be associated with a decrease in the discharge rate of the neurons in these sites.

\section{Metabolic mapping vs functional anatomy}

From the considerations discussed above, it is clear that DG mapping experiments must be interpreted with caution. It is possible to induce behavioral changes with stimulation rates that cause little or no change in cerebral metabolism within relevant pathways. The use of frequent or intense stimuli to label all sites may produce unphysiologic patterns by activating areas unrelated to the behavior. Indeed, it could be argued that the stimulated behavior itself is unphysiologic and the resultant metabolic map teaches little of the use of pathways during natural behavior (see Roberts, 1980, for discussion). Nevertheless, with these qualifications in mind, metabolic mapping techniques can give useful data of a unique kind. With respect to the forelimb motor cortex, three final observations seem warranted. First, it is interesting to note from our dose-response study how even weak stimulation of a cortical point activated nearly all corticocortical pathways available for use. This would seem to indicate that cortical discharges readily send direct or collateral discharges widely throughout cortex. In this study, corticocortical circuits originating from supragranular pyramidal cells might have been preferentially activated by proximity to the cathodal pole of the electrode. Second, the motor cortex exerts a direct and prominent influence on activity in dorsal thalamus. Indeed, the quantitative data of our pathway and mapping experiments seem to suggest that a major role of motor cortex is to interact with activity in sites afferent to the motor cortex. Finally, whereas some polysynaptic pathways seemingly available for use are never activated, others are activated in great strength. Reasons for this must be sought in experiments employing other techniques. With respect to the strong output 
of motor cortex through the ventral corridor of basal ganglia, it will be necessary to learn how motor activity is orchestrated through sequential inhibitory synapses.

\section{References}

Akers, R. M., and H. P. Killackey (1978) Organization of corticocortical connections in the parietal cortex of the rat. J. Comp. Neurol. 181: 513-538.

Auker, C. R., R. M. Meszler, and D. O. Carpenter (1983) Apparant discrepancy between single-unit activity and [14C]deoxyglucose labeling in optic tectum of the rattlesnake. J. Neurophysiol. 49: 15041516 .

Beckstead, R. M., V. B. Domesick, and W. J. H. Nauta (1979) Efferent connections of the substantia nigra and ventral tegmental area in rat. Brain Res. 175: 191-217.

Bower, J. M., D. H. Beerman, J. M. Gibson, G. M. Shambes, and W. Welker (1981) Principles of organization of a cerebro-cerebellar circuit. Brain Behav. Evol. 18: 1-18.

Carter, D. A., and H. C. Fibiger (1978) The projections of the entopeduncular nucleus and the globus pallidus in rat as demonstrated by autoradiography and horseradish peroxidase histochemistry. J. Comp. Neurol. 177: 113-124.

Chapin, J. K., and D. J. Woodward (1982) Cortic-cortical connections between physiologically and histologically defined zones in the rat SI and MI cortices. Neurosci. Abstr. 8: 853.

Collins, R. C. (1978a) Use of cortical circuits during focal penicillin seizures: An autoradiographic study with [14C]deoxyglucose. Brain Res. 150: 487-501.

Collins, R. C. (1978b) Kindling of neuroanatomic pathways during recurrent focal penicillin seizures. Brain Res. 150: 503-517.

Collins, R. C. (1980) Intracortical localization of 2-deoxyglucose metabolism: On-off metabolic columns. In Cerebral Metabolism and Neural Function, J. V. Passonneau, R. A. Hawkins, W. D. Lust, and F. A. Welsh, eds., Chap. 37, pp. 338-351, Williams \& Wilkins, Baltimore, MD.

Collins, R. C., and T. V. Caston (1979) Functional anatomy of occipital lobe seizures: An experimental study in rats. Neurology 29:705-716.

Collins, R. C., and T. Der (1979) Quantitative subcortical distribution of efferent projections from motor cortex in rat. Neurosci. Abstr. 5: 366.

Collins, R. C., and I. Divac (1984) Neostriatal participation in prosencephalic systems: Evidence from deoxyglucose autoradiography. In Advances in Neurology, Vol. 40, R. G. Hassler and J. F. Christ, eds., pp. 117-122, Raven, New York.

Collins, R. C., C. Kennedy, L. Sokoloff, and F. Plum (1976) Metabolic anatomy of focal motor seizures. Arch. Neurol. 33: 536-542.

Collins, R. C., T. Der, E. W. Lothman, and E. F. Vastola (1980) Demonstration of motor circuits with cortical stimulation and 14C-deoxyglucose autoradiography. Neurosci. Abstr. 6: 58 .

DeLong, M. R., and A. P. Georgopoulos (1981) Motor functions of the basal ganglia. In Handbook of Physiology. The Nervous System, Vol. 2, Pt. 2, J. M. Brookhart and V. B. Mountcastle, eds., Chap. 21, pp. 1017-1061, American Physiological Society, Washington, DC.

Der, T., E. S. Santori, and R. C. Collins (1983) Functional cerebellar metabolism during forelimb movement in the rat. Neurosci. Abstr. 9: 224.

Divac, I., and N. H. Dimer (1980) Prefrontal system in rat visualized by means of labeled deoxyglucose-further evidence for functional heterogeneity of neostriatum. J. Comp. Neurol. 190: 1-13.

Donoghue, J. P., and C. Parham (1983) Afferent connections of the lateral agranular field of the rat motor cortex. J. Comp. Neurol. 217 : $390-404$.

Donoghue, J. P., and S. P. Wise (1982) The motor cortex of the rat: Cytoarchitecture and microstimulation mapping. J. Comp. Neurol. 212: 76-88.

Donoghue, J. P., K. L. Kerman, and F. L. Ebner (1979) Evidence for two organizational plans within the somatic sensory-motor cortex of the rat. J. Comp. Neurol. 183: 647-664.

Faull, R. L. M., and J. B. Carman (1968) Ascending projections of the substantia nigra in the rat. J. Comp. Neurol. 132: 73-92.

Faull, R. L. M., and J. B. Carman (1978) The cerebellofugal projections in the brachium conjunctivum in the rat. I. The contralateral ascending pathway. J. Comp. Neurol. 178: 495-518.

Hall, R. D., and E. P. Lindholm (1974) Organization of motor and somatosensory neocortex in the albino rat. Brain Res. 66: 23-38.
Hurlbut, W. P. (1970) Ion movements in nerve. In Membranes and Ion Transport, E. E. Bittar, ed., pp. 95-143, Wiley-Interscience, New York.

Isseroff, A., M. L. Schwartz, J. J. Dekker, and P. S. Goldman-Rakic (1984) Columnar organization of callosal and associational projections from rat frontal cortex. Brain Res. 293: 213-223.

Jankowska, E., Y. Padel, and R. Tanaka (1975) The mode of activation of pyramidal tract cells by intracortical stimuli. J. Physiol. (Lond.) 249: 617-636.

Joscph, J. W., G. M. Shambcs, J. M. Gibson, and W. Welker (1978) Tactile projections to granule cells in the caudal vermis of the rat's cerebellum. Brain Behav. Evol. 15: 141-149.

Krettek, J. E., and J. L. Price (1977) The cortical projections of the mediodorsal thalamic nucleus and adjacent thalamic nuclei in the rat. J. Comp. Neurol. 171: 157-191.

Lothman, E., J. LaManna, G. Cordingly, M. Rosenthal, and G. Somjen (1975) Responses of electrical potential, potassium levels, and oxidative metabolic activity of the cerebral neocortex of cats. Brain Res. 88: $15-36$.

Mata, M., D. J. Fink, H. Gainer, C. B. Smith, L. Davidson, H. Savaki, W. J. Schwartz, and L. Sokoloff (1980) Activity-dependent energy metabolism in rat posterior pituitary primarily reflects sodium pump activity. J. Neurochem. 34: 213-215.

Nagy, J. I., D. A. Carter, and H. C. Fibiger (1978) Anterior striata projections to the globus pallidus, entopeduncular nucleus and substantia nigra in the rat: The gaba connection. Brain Res. 158: 15-29.

Neafsey, E. J., and C. Sievert (1982) A second forelimb area exists in the rat frontal cortex. Brain Res. 232: 151-156.

Penney, J. B., and A. B. Young (1983) Speculations on the functional anatomy of basal ganglia disorders. Annu. Rev. Neurosci. 6: 73-94.

Ranck, J. B., Jr. (1975) Which elements are excited in electrical stimulation of mammalian central nervous system: A review. Brain Res. 98: 417-440.

Roberts, W. W. (1980) [14C] Deoxyglucose mapping of first-order projections activated by stimulation of hypothalamic lateral sites eliciting gnawing, eating, and drinking in rats. J. Comp. Neurol. 194: 617-638.

Sanderson, K. J., W. Welker, and G. M. Shambes (1984) Reevaluation of motor cortex and of sensorimotor overlap in cerebral cortex of albino rats. Brain Res. 292: 251-260.

Santori, E. M., T. Der, and R. C. Collins (1986) Functional metabolic mapping during forelimb movement in rat. II. Stimulation of forelimb muscles. J. Neurosci. 6: 463-472.

Savaki, H. E., M. Desban, J. Glowinski, and M. Besson (1983a) Local cerebral glucose consumption in the rat. I. Effects of halothane anesthesia. J. Comp. Neurol. 213: 36-45.

Savaki, H. E., M. Desban, J. Glowinski, and M. Besson (1983b) Local cerebral glucose utilization in the rat. II. Effects of unilateral substantia nigra stimulation in conscious and in halothane-anesthetized animals. J. Comp. Neurol. 213: 46-65.

Schoppmann, A., and M. P. Stryker (1981) Physiological evidence that the 2-deoxyglucose method reveals orientation columns in cat visual cortex. Nature 293: 574-576.

Schwartz, W. J., and H. Gainer (1977) Suprachiasmatic nucleus: Use of 14C-labeled deoxyglucose uptake as a functional marker. Science 197: 1089-1091.

Settlage, P. H., W. G. Bingham, H. M. Suckle, A. F. Borge, and C. N. Woolsey (1949) The pattern of localization in the motor cortex of the rat. Fed. Proc. 8: 144.

Shambes, G. M., J. M. Gibson, and W. Welker (1978) Fractured somatotopy in granule cell tactile areas of rat cerebellar hemispheres revealed by micromapping. Brain Behav. Evol. 15: 94-140.

Sharp, F. R. (1984) Regional (14C) 2-dcoxyglucosc uptake during forelimb movements evoked by rat motor cortex stimulation: Cortex, diencephalon, midbrain. J. Comp. Neurol. 224: 259-285.

Sharp, F. K., and K. Evans (1982) Kegional (14C) 2-deoxyglucose uptake during vibrissae movements evoked by rat motor cortex stimulation. J. Comp. Neurol. 208: 255-287.

Sharp, F. R., and A. F. Ryan (1984) Regional (14C) 2-deoxyglucose uptake during forelimb movements evoked by rat motor cortex stimulation: Pons, cerebellum, spinal cord, muscle. J. Comp. Neurol. 224: 286-306.

Sokoloff, L. (1984) Metabolic Probes of Central Nervous System Activity in Animals and Man. Magnes Lecture Series, Vol. 1, Sinaur, Sunderland, MA. 
Sokoloff, L., M. Reivich, C. Kennedy, M. H. Des Rosiers, C. S. Patlak, K. D. Pettigrew, O. Sakurada, and M. Shinohara (1977) The [14C]deoxyglucose method for the measurement of local cerebral glucose utilization: Theory, procedure, and normal values in the conscious and anesthetized albino rat. J. Neurochem. 28: 897-916.

Somogyi, P., J. P. Bolam, and A. D. Smith (1981) Monosynaptic cortical input and local collaterals of identified striatonigral neurons. A light and electron microscopic study using the Golgi-peroxidase transport degeneration procedure. J. Comp. Neurol. 195: 567-584.

Theurich, M., C. M. Müller, and H. Scheich (1984) 2-Deoxyglucose accumulation parallels extracellular recorded spike activity in the avian auditory neostriatum. Brain Res. 322: 157-161.

Toga, A. W., and R. C. Collins (1981) Metabolic response of optic centers to visual stimuli in albino rat. Anatomic and physiologic considerations. J. Comp. Neurol. 199: 443-464.

Toga, A. W., R. L. Goo, R. Murphy, and R. C. Collins (1984) Neuroscience application of interactive image analysis. Opt. Eng. 23:279282.

Webster, K. E. (1961) Cortico-striate interrelations in the albino rat. J. Anat. 95: 532-544.

Welker, C. (1971) Microelectrode delineation of fine grain somatotopic organization of SmI cerebral cortex in albino rat. Brain Res. 26:259275.
Welker, W., K. J. Sanderson, and G. M. Shambes (1982) Definition of somatosensory transitional zones (TR) in the sensorimotor (SI-MI) cerebral cortex of rats. Neurosci. Abstr. 8: 36 .

Welker, W., K. J. Sanderson, and G. M. Shambes (1984) Pattcrns of afferent projections to transitional zones in the somatic sensorimotor cerebral cortex of albino rats. Brain Res. 292: 261-267.

Wise, S. P., and E. G. Jones (1976) The organization and postnatal development of the commissural projections of the rat somatic sensory cortex. J. Comp. Neurol. 168: 313-344.

Wise, S. P., and E. G. Jones (1977) Cells of origin and terminal distribution of descending projections of the rat somatic sensory cortex. J. Comp. Neurol. 175: 129-158.

Wise, S. P., E. A. Murray, and J. D. Coulter (1979) Somatotopic organization of corticospinal and corticotrigeminal neurons in the rat. Neuroscience 4: 65-78.

Woolsey, C. N. (1958) Organization of somatic sensory and motor areas of the cerebral cortex. In Biological and Biochemical Basis of Behavior, H. Harlow and C. N. Woolscy, cds., pp. 63-81, University of Wisconsin Press, Madison, WI.

Yoshida, M., A. Rabin, and M. Anderson (1972) Monosynaptic inhibition of pallidal neurons by axon collaterals of caudate-nigral fibers. Exp. Brain Res. 15: 333-347. 